\title{
Sensitivity of Mixed-Phase Cloud Optical Properties to Cloud Particle Model and Microphysical Factors at Wavelengths from 0.2 to $100 \mu \mathrm{m}$
}

\author{
Qing Luo ${ }^{1}$, Bingqi Yi ${ }^{1,2, *(D)}$ and Lei Bi ${ }^{3}(\mathbb{D}$ \\ 1 School of Atmospheric Sciences and Guangdong Province Key Laboratory for Climate Change and Natural \\ Disaster Studies, Sun Yat-sen University, Guangzhou 510275, China; luoq55@mail2.sysu.edu.cn \\ 2 Southern Marine Science and Engineering Guangdong Laboratory (Zhuhai), Zhuhai 519082, China \\ 3 Department of Atmospheric Sciences, School of Earth Sciences, Zhejiang University, Hangzhou 310027, China; \\ bilei@zju.edu.cn \\ * Correspondence: yibq@mail.sysu.edu.cn
}

check for updates

Citation: Luo, Q.; Yi, B.; Bi, L. Sensitivity of Mixed-Phase Cloud Optical Properties to Cloud Particle Model and Microphysical Factors at Wavelengths from 0.2 to $100 \mu \mathrm{m}$. Remote Sens. 2021, 13, 2330. https:/ / doi.org/10.3390/rs13122330

Academic Editor: Maria João Costa

Received: 17 April 2021

Accepted: 10 June 2021

Published: 14 June 2021

Publisher's Note: MDPI stays neutral with regard to jurisdictional claims in published maps and institutional affiliations.

Copyright: (c) 2021 by the authors. Licensee MDPI, Basel, Switzerland. This article is an open access article distributed under the terms and conditions of the Creative Commons Attribution (CC BY) license (https:/ / creativecommons.org/licenses/by/ $4.0 /)$.

\begin{abstract}
The representation of mixed-phase cloud optical properties in models is a critical problem in cloud modeling studies. Ice and liquid water co-existing in a cloud layer result in significantly different cloud optical properties from those of liquid water and ice clouds. However, it is not clear as to how mixed-phase cloud optical properties are affected by various microphysical factors, including the effective particle size, ice volume fraction, and ice particle shape. In this paper, the optical properties (extinction efficiency, scattering efficiency, single scattering albedo, and asymmetry factor) of mixed-phase cloud were calculated assuming externally and internally mixed cloud particle models in a broad spectral range of $0.2-100 \mu \mathrm{m}$ at various effective particle diameters and ice volume fraction conditions. The influences of various microphysical factors on optical properties were comprehensively examined. For the externally mixed cloud particles, the shapes of ice crystals were found to become more important as the ice volume fraction increases. Compared with the mixed-phase cloud with larger effective diameter, the shape of ice crystals has a greater impact on the optical properties of the mixed-phase cloud with a smaller effective diameter $(<20 \mu \mathrm{m})$. The optical properties calculated by internally and externally mixed models are similar in the longwave spectrum, while the optical properties of the externally mixed model are more sensitive to variations in ice volume fraction in the solar spectral region. The bulk scattering phase functions were also examined and compared. The results indicate that more in-depth analysis is needed to explore the radiative properties and impacts of mixed-phase clouds.
\end{abstract}

Keywords: mixed-phase clouds; optical properties; ice crystal habits

\section{Introduction}

Clouds are fundamentally important in the Earth's radiation budget and climate change [1-3]. The macrophysical and microphysical properties of clouds affect their capability to absorb and scatter radiation. Clouds can be classified as ice cloud, liquid water cloud, and mixed-phase cloud according to the thermal phase of water in clouds. The mixed-phase state has a great influence on cloud albedo [4]. Yan et al. [5] analyzed satellite retrieval data from active remote sensors and found that mixed-phase clouds have a strong warming effect in the Arctic during the boreal cold season (September to May), while a strong cooling effect was found on the Tibetan Plateau in boreal summer. The presence of mixed-phase as compared to ice clouds may also significantly affect the structure of the boundary layer and large-scale dynamics through cloud-top radiative cooling [6]. It is evident that mixed-phase clouds have distinct radiative impacts when compared with single-phase clouds but their optical properties have not been well understood. Thus, it is necessary to reasonably represent mixed-phase clouds in the numerical models for weather forecasting and climate prediction [7]. 
Mixed-phase clouds are commonly found in the troposphere and occur at all latitudes [8]. In climate modeling studies, the presence of ice in clouds below cirrus is often ignored [9]. For the temperature range where liquid water and ice can co-exist, precise measurements of the bulk liquid fraction of clouds are required before the single scattering properties of mixed-phase cloud can be applied to large-scale models [10]. When cloud temperature is between -40 and $0{ }^{\circ} \mathrm{C}$, mixed-phase cloud consisting of ice crystals and liquid droplets is common in the earth's atmosphere [11,12]. Among the clouds collected by the First International Satellite Cloud Climatology Project Regional Experiment (FIRE) Arctic Clouds Experiment, 33\% of clouds were identified as mixed-phase, and 16\% and $51 \%$ of clouds were identified as liquid and ice phase, respectively [10]. In the Arctic mixedphase cloud experiment and the Arctic environmental change study, the mixed-phase clouds appeared in $4 \%$ to $26 \%$ of the observation period, depending on the season and location [13]. At -10 to $0{ }^{\circ} \mathrm{C}$, mixed-phase clouds constitute $17-37 \%$ of in situ airborne observations over the Southern Ocean [14].

The amount of ice in mixed-phase cloud is fundamentally important to determine the radiative properties. Sassen [15] pointed out that adding a small amount of supercooled liquid water to high cumulus clouds could greatly increase cloud albedo. Ice fraction in mixed-phase cloud remarkably influences the cloud optical depth [16]. Cober et al. [17] and Vidaurre and Hallett [18] found the ice volume fraction in mixed-phase clouds is mostly less than 0.1 or greater than 0.8 . For mixed-phase clouds sampled in situ during FIRE Arctic clouds experiment, more than $87 \%$ of the clouds contain over $90 \%$ of supercooled water droplets $[10,19]$. Analysis showed that if the cloud is assumed to be in a pure liquid/ice phase, the effective diameter and the corresponding optical thickness of the cloud could be overestimated/underestimated [20]. Sassen et al. [21] confirmed that the radiative characteristics and radar backscattering characteristics of clouds were determined by the relative amount of liquid water droplets and ice crystals in cloud by numerical experiments using an explicit cloud microphysical model. Given the sensitivity of equilibrium climate to cloud phase feedback under the $2 \mathrm{xCO}_{2}$ climate scenario, the supercooled liquid fraction of mixed-phase clouds needs to be accurately expressed in the global climate models [22].

The mixture model of mixed-phase cloud can seriously affect the single scattering albedo, thus affecting the radiative heating profile of cloud and the temporal evolution of cloud systems [10]. Cloud albedo and the rate of albedo change with ice fraction depend remarkably on the mixture model [16]. It is commonly assumed that the ice crystals and liquid water droplets in mixed-phase cloud are in the externally mixed state [23]. Liquid water droplets and ice crystals can also be mixed inhomogeneously in the form of singlephase clusters [8]. Sikand et al. [24] used a cloud model assuming adjacent layers of liquid droplets and ice crystals from top to bottom to simulate mixed-phase cloud layer based on the images taken by the cloud particle imager.

Ice crystal shapes are also important for the microphysical and radiative properties of Arctic clouds, especially for mixed-phase clouds with small ice crystals and large ice volume fractions [25]. Surface net fluxes and cloud absorption may vary by up to $15 \mathrm{~W} / \mathrm{m}^{2}$, depending on the ice crystal shapes [26]. In early radiative transfer models, ice crystals are described as spheres [27], while in later studies ice crystals are regarded as long cylinders [28] or smooth solid hexagonal columns [29]. The microphysical data of the mixed-phase clouds collected by aircraft measurements showed various ice crystal habits including regular spheres, plates, columns, bullet rosettes, and irregular aggregates [30-33]. Different computational methods are implemented to study the optical properties of irregular ice crystals with simple and complex geometries such as multi-shape ice mixture models [34-38]. Chen and Zhang [39] further showed the selection of weights of different ice crystal shapes in multi-shape model has a great influence on longwave band-averaged volume extinction coefficient, single scattering albedo, and asymmetry factor of ice clouds. However, similar studies for mixed-phase cloud are scarce.

In this study, we closely examined the sensitivity of the optical properties of mixedphase clouds to various factors including effective particle diameter, ice volume fraction, 
ice crystal shape, and the mixture model. This study also features the optical properties of mixed-phase cloud over a broad spectral range from 0.2 to $100 \mu \mathrm{m}$, which is of great importance for retrieving the optical properties of mixed-phase clouds by satellites and for modeling the radiative impacts of mixed-phase clouds in earth system models. The externally mixed model and the internally mixed model are introduced to calculate the optical properties of the mixed-phase cloud and the computed results based on these two models are compared. In Section 2, data and models used are illustrated and the methods to derive the optical properties of different cloud models are introduced. In Section 3, the sensitivity of mixed-phase cloud optical property to different models are summarized. The influence of various factors on the optical properties of mixed-phase cloud is also discussed. Summary and conclusions are given in Section 4.

\section{Models and Methods}

\subsection{Particle Size Distributions}

In real clouds, cloud particles have various sizes and follow certain size distributions. The particle size distribution (PSD) is often specified with respect to the maximum dimension D of individual particles [35]. Typically, cloud particle size distributions follow lognormal distributions [40], gamma distributions [41-43], and exponential distributions [44]. We employ the gamma distribution [41] PSD in the form of:

$$
\mathrm{N}(\mathrm{D})=\mathrm{N}_{0} \mathrm{D}^{\mu} \exp (-\Lambda \mathrm{D})=\mathrm{N}_{0} \mathrm{D}^{\left(1-3 v_{e f f}\right) / v_{e f f}} \exp \left(-\frac{\mathrm{D}}{\mathrm{D}_{\mathrm{e}} v_{\text {eff }}}\right),
$$

where $\mathrm{N}_{0}, \mu$, and $\Lambda$ are the intercept parameter, shape parameter, and slope parameter, respectively. $D_{\mathrm{e}}$ is the effective diameter and $v_{\text {eff }}$ is the effective variance. Note the effective variance of PSD could vary depending on the study case.

\subsection{Mixed-Phase Cloud Particle Models}

Externally and internally mixed particle models are both evaluated in this study. For the externally mixed model, ice crystals and liquid water droplets are assumed to be independent in the process of radiation transmission. Spherical liquid water droplets and non-spherical ice crystals are assumed to be uniformly mixed. However, it should be noted that liquid water droplets and ice crystals are not always homogeneously mixed in real clouds. The effective diameter of the externally mixed cloud is used to represent the bulk measure of particle size for the cloud system. For independently scattering particles of mixed-phase cloud with a certain PSD, the effective diameter $\mathrm{D}_{\mathrm{e}}$ can be expressed as the weighted sum of the effective diameters of ice crystals and liquid water droplets [23]:

$$
D_{e}=\frac{3}{2} \frac{\int_{D_{\min }}^{D_{\max }} V_{i}(D) N_{i}(D) d D+\int_{D_{\min }}^{D_{\max }} V_{w}(D) N_{w}(D) d D}{\int_{D_{\min }}^{D_{\max }} A_{i}(D) N_{i}(D) d D+\int_{D_{\min }}^{D_{\max }} A_{W}(D) N_{w}(D) d D},
$$

where $D_{\min }$ and $D_{\max }$ describe the lower and upper limits of individual particle size, and $\mathrm{A}$ and $\mathrm{V}$ are the projected area and volume of an individual particle. The subscripts $\mathrm{i}$ and $\mathrm{w}$ indicate ice crystal and liquid water, respectively.

The coated sphere model, which is a simplified and effective model for internally mixed cases, is used to improve the calculation efficiency. Using coated sphere model to specify internally mixed aerosol properties in previous studies is a common practice [45-47]. Wang et al. [48] used a two-layer model to study the heterogeneity of sea salt aerosols and found that the optical properties of wet sea salt aerosols simulated by the coated sphere model and the coated non-sphere model are very close. However, cloud particles have much larger sizes than those of aerosol particles and are highly non-spherical in shape. It is necessary to know whether the coated sphere model is a reasonable replacement of coated non-sphere model for mixed-phase clouds. 
A set of comparisons was carried out between the coated sphere and coated nonsphere models at a few selected wavelengths and particle sizes. Ice sphere and single hexagonal ice column with identical volume are designated as inner cores. The inner cores were coated with liquid water shell with the same diameter. Cases with various sizes of inner cores were also tested. The computed optical properties of mixed-phase cloud particles with size parameters of 25 and 50 are shown in Tables 1 and 2, respectively. It is evident that the results of coated sphere and coated non-sphere cases are very similar. The scattering phase functions of the coated sphere model and the coated non-sphere model are given in Appendix A to show their high level of consistency. Thus, it is deemed reasonable to use the coated sphere model to represent the internally mixed-phase cloud model. Note the size parameter of mixed-phase cloud particle examined here (a maximum of 50) was not quite large, especially for shortwave, and the difference between coated non-sphere and coated sphere models could become larger as the size parameter increases.

Table 1. Extinction efficiency ( $\left.Q_{\text {ext }}\right)$, scattering efficiency $\left(\mathrm{Q}_{\text {sca }}\right)$, and asymmetry factor $(\mathrm{g})$ of coated sphere and coated non-sphere models with various size parameters of core $\left(\mathrm{x}_{\text {core }}\right)$ at four representative wavelengths $(\lambda)$. The size parameter of shell is 25 .

\begin{tabular}{ccccccccc}
\hline & \multicolumn{3}{c}{ Coated Sphere Model } & \multicolumn{4}{c}{ Coated Non-Sphere Model } \\
\hline $\boldsymbol{\lambda}(\boldsymbol{\mu \mathrm { m }})$ & $\mathbf{x}_{\text {core }}$ & $\mathbf{Q}_{\text {ext }}$ & $\mathbf{Q}_{\text {sca }}$ & $\mathbf{g}$ & $\mathbf{x}_{\text {core }}$ & $\mathbf{Q}_{\text {ext }}$ & $\mathbf{Q}_{\text {sca }}$ & $\mathbf{g}$ \\
\hline \multirow{2}{*}{0.65} & 5 & 2.5071 & 2.5040 & 0.8584 & 5.9 & 2.5040 & 2.5040 & 0.8589 \\
& 15 & 2.2612 & 2.3267 & 0.8535 & 17.7 & 2.3267 & 2.3267 & 0.7798 \\
\multirow{2}{*}{1.6} & 5 & 2.1252 & 2.1291 & 0.8468 & 5.9 & 2.1291 & 2.1291 & 0.8473 \\
& 15 & 1.8730 & 1.8998 & 0.8317 & 17.7 & 1.8998 & 1.8998 & 0.8330 \\
8 & 5 & 1.1306 & 1.1291 & 0.9584 & 5.9 & 1.1291 & 1.1291 & 0.9526 \\
& 15 & 1.1190 & 1.1330 & 0.9573 & 17.7 & 1.1330 & 1.1330 & 0.9581 \\
30 & 5 & 1.1695 & 1.1689 & 0.9324 & 5.9 & 1.1689 & 1.1689 & 0.9328 \\
& 10 & 1.1695 & 1.1689 & 0.9324 & 12.6 & 1.1689 & 1.1689 & 0.9328 \\
\hline
\end{tabular}

Table 2. Same as Table 1, except that the size parameter of shell is 50.

\begin{tabular}{ccccccccc}
\hline & \multicolumn{3}{c}{ Coated Sphere Model } & \multicolumn{3}{c}{ Coated Non-Sphere Model } \\
\hline $\boldsymbol{\lambda}(\boldsymbol{\mu \mathrm { m } )}$ & $\mathbf{x}_{\text {core }}$ & $\mathbf{Q}_{\text {ext }}$ & $\mathbf{Q}_{\text {sca }}$ & $\mathbf{g}$ & $\mathbf{x}_{\text {core }}$ & $\mathbf{Q}_{\text {ext }}$ & $\mathbf{Q}_{\text {sca }}$ & $\mathbf{g}$ \\
\hline \multirow{2}{*}{0.65} & 15 & 1.9072 & 1.9072 & 0.8470 & 17.7 & 1.9119 & 1.9119 & 0.8477 \\
& 30 & 2.0378 & 2.0378 & 0.8620 & 35.4 & 2.0621 & 2.0621 & 0.8626 \\
\multirow{2}{*}{1.6} & 15 & 2.2958 & 2.2773 & 0.8808 & 17.7 & 2.2695 & 2.2511 & 0.8789 \\
& 30 & 2.3068 & 2.2805 & 0.8846 & 35.4 & 2.2890 & 2.2645 & 0.8824 \\
\multirow{2}{*}{8} & 15 & 2.1452 & 1.1021 & 0.9749 & 17.7 & 2.1438 & 1.1005 & 0.9750 \\
& 30 & 2.1454 & 1.1018 & 0.9749 & 35.4 & 2.1455 & 1.1018 & 0.9750 \\
\multirow{3}{*}{30} & 15 & 2.1378 & 1.1609 & 0.9361 & 23.2 & 2.1379 & 1.1603 & 0.9365 \\
& 20 & 2.1378 & 1.1609 & 0.9361 & 35.7 & 2.1379 & 1.1603 & 0.9365 \\
\hline
\end{tabular}

In this study, the coated sphere model is used to characterize the internally mixedphase cloud. We only consider the case having spherical ice core coated with liquid water. The maximum dimension $\mathrm{L}$ of coated sphere model is the diameter of the shell, and the effective diameter $D_{c s}$ for a given PSD is defined as:

$$
\mathrm{D}_{\mathrm{CS}}=\frac{3}{2} \frac{\int_{\mathrm{L}_{\min }}^{\mathrm{L}_{\max }} \mathrm{V}_{\mathrm{cs}}(\mathrm{L}) \mathrm{N}(\mathrm{L}) \mathrm{dL}}{\int_{\mathrm{L}_{\min }}^{\mathrm{L}_{\max }} \mathrm{A}_{\mathrm{cs}}(\mathrm{L}) \mathrm{N}(\mathrm{L}) \mathrm{dL}},
$$

where $\mathrm{A}_{\mathrm{cs}}$ and $\mathrm{V}_{\mathrm{cs}}$ are the projected area and volume of coated sphere model, respectively.

\subsection{Formulation of Optical Properties}

The key optical properties for cloud scattering calculations include extinction efficiency, scattering efficiency, single scattering albedo, and asymmetry factor. The invariant 
imbedding T-matrix method [49-52] is used to calculate the single scattering properties of the internally mixed cloud model. The shape of liquid water droplet can be regarded as a homogeneous sphere and their optical properties are calculated by the Lorenz-Mie theory [53]. The ice particle scattering property database [36,54] is employed to supply the ice scattering properties of various non-spherical ice particles over a broad spectrum ranging from 0.2 to $100 \mu \mathrm{m}$. The particle size in this database is from 2 to $10,000 \mu \mathrm{m}$. Nine ice particle shapes, which include droxtal, hexagonal column, plate, hollow column, hollow bullet rosette (HBR), solid bullet rosette (SBR), 8-element column aggregate (8-column), 5-element plate aggregate (5-plate), and 10-element plate aggregate (10-plate) are selected to provide a comprehensive examination of the impacts of ice particle shape on mixed-phase cloud properties. For optical calculations, we adopt the ice complex refractive indices from Warren and Brandt [55], which are also used for constructing the ice optics database [36,54]. The liquid water cloud complex refractive indices measured by Hale and Querry [56], Palmer and Williams [57], and Downing and Williams [58] are used.

At a specific wavelength $\lambda$, the bulk extinction efficiency $\overline{\mathrm{Q}}_{\mathrm{ext}}$ is the extinction cross section divided by the total projected area over a given PSD [59] in the form of:

$$
\overline{\mathrm{Q}}_{\mathrm{ext}}(\lambda)=\frac{\int_{\mathrm{D}_{\min }}^{\mathrm{D}_{\max }} \mathrm{Q}_{\mathrm{ext}}(\mathrm{D}, \lambda) \mathrm{A}(\mathrm{D}) \mathrm{N}(\mathrm{D}) \mathrm{dD}}{\int_{D_{\min }}^{D_{\max }} \mathrm{A}(\mathrm{D}) \mathrm{N}(\mathrm{D}) \mathrm{dD}},
$$

where $Q_{\text {ext }}$ is the extinction efficiency of an individual ice or liquid water particle. Similarly, the bulk scattering efficiency, asymmetry factor, and single scattering albedo can be derived as:

$$
\begin{gathered}
\overline{\mathrm{Q}}_{\mathrm{sca}}(\lambda)=\frac{\int_{\mathrm{D}_{\min }}^{D_{\max }} \mathrm{Q}_{\mathrm{sca}}(\mathrm{D}, \lambda) \mathrm{A}(\mathrm{D}) \mathrm{N}(\mathrm{D}) \mathrm{dD}}{\int_{D_{\min }}^{D_{\max }} \mathrm{A}(\mathrm{D}) \mathrm{N}(\mathrm{D}) \mathrm{dD}}, \\
\overline{\mathrm{g}}(\lambda)=\frac{\int_{\mathrm{D}_{\min }}^{D_{\max }} \mathrm{g}(\mathrm{D}, \lambda) \mathrm{Q}_{\mathrm{sca}}(\mathrm{D}, \lambda) \mathrm{A}(\mathrm{D}) \mathrm{N}(\mathrm{D}) \mathrm{dD}}{\int_{\mathrm{D}_{\min }}^{D_{\max }} \mathrm{Q}_{\mathrm{sca}}(\mathrm{D}, \lambda) \mathrm{A}(\mathrm{D}) \mathrm{N}(\mathrm{D}) \mathrm{dD}}, \\
\bar{\omega}(\lambda)=\frac{\overline{\mathrm{Q}}_{\text {sca }}(\lambda)}{\overline{\mathrm{Q}}_{\text {ext }}(\lambda)},
\end{gathered}
$$

where $Q_{\text {sca }}(\lambda), \omega(\lambda)$, and $g(\lambda)$ are the scattering efficiency, single scattering albedo, and asymmetry factor of an individual ice or liquid water particle. $\overline{\mathrm{Q}}_{\text {sca }}(\lambda), \bar{g}(\lambda)$, and $\bar{\omega}(\lambda)$ are the bulk scattering efficiency, asymmetry factor, and single scattering albedo for clouds with a given PSD, respectively.

The bulk scattering phase function $\bar{p}(\theta, \lambda)$ is given by:

$$
\bar{p}(\theta, \lambda)=\frac{\int_{D_{\min }}^{D_{\max }} p(\theta, D, \lambda) Q_{\text {sca }}(D, \lambda) A(D) N(D) d D}{\int_{D_{\min }}^{D_{\max }} Q_{\text {sca }}(D, \lambda) A(D) N(D) d D},
$$

where $p(\theta, D, \lambda)$ is the phase function of each individual particle.

The equations for calculating the optical properties of externally mixed cloud model are derived following those of Yang et al. [23], which are formulated on the basis of fundamental physics instead of a linear weighting of the contribution of ice and water properties. It is worth noting that the ice mass fraction used in the formula in Yang et al. [23] is replaced by ice volume fraction in this study. The equations for the bulk extinction efficiency $\overline{\mathrm{Q}}_{e, \text { ext }}(\lambda)$, scattering efficiency $\overline{\mathrm{Q}}_{\mathrm{e}, \mathrm{sca}}(\lambda)$, asymmetry factor $\overline{\mathrm{g}}_{\mathrm{e}}(\lambda)$, single scattering albedo $\bar{\omega}_{e}(\lambda)$, and scattering phase function $\bar{p}_{e}(\theta, \lambda)$ of the mixed-phase cloud in externally mixed state at a specific wavelength are given as:

$$
\overline{\mathrm{Q}}_{\mathrm{e}, \mathrm{ext}}(\lambda)=\overline{\mathrm{Q}}_{\mathrm{ext}, \mathrm{i}}(\lambda) \frac{\mathrm{D}_{\mathrm{e}}}{\mathrm{D}_{\mathrm{e}, \mathrm{i}}} \phi+\overline{\mathrm{Q}}_{\mathrm{ext}, \mathrm{w}}(\lambda) \frac{\mathrm{D}_{\mathrm{e}}}{\mathrm{D}_{\mathrm{e}, \mathrm{w}}}(1-\phi),
$$




$$
\begin{gathered}
\overline{\mathrm{Q}}_{\mathrm{e}, \mathrm{sca}}(\lambda)=\overline{\mathrm{Q}}_{\mathrm{sca}, \mathrm{i}}(\lambda) \frac{\mathrm{D}_{\mathrm{e}}}{\mathrm{D}_{\mathrm{e}, \mathrm{i}}} \phi+\overline{\mathrm{Q}}_{\mathrm{sca}, \mathrm{w}}(\lambda) \frac{\mathrm{D}_{\mathrm{e}}}{\mathrm{D}_{\mathrm{e}, \mathrm{w}}}(1-\phi), \\
\overline{\mathrm{g}}_{\mathrm{e}}(\lambda)=\overline{\mathrm{g}}_{\mathrm{i}}(\lambda) \frac{\overline{\mathrm{Q}}_{\mathrm{sca}, \mathrm{i}}(\lambda)}{\overline{\mathrm{Q}}_{\mathrm{e}, \mathrm{sca}}(\lambda)} \frac{\mathrm{D}_{\mathrm{e}}}{\mathrm{D}_{\mathrm{e}, \mathrm{i}}} \phi+\overline{\mathrm{g}}_{\mathrm{w}}(\lambda) \frac{\overline{\mathrm{Q}}_{\mathrm{sca}, \mathrm{w}}(\lambda)}{\overline{\mathrm{Q}}_{\mathrm{e}, \mathrm{sca}}(\lambda)} \frac{\mathrm{D}_{\mathrm{e}}}{\mathrm{D}_{\mathrm{e}, \mathrm{w}}}(1-\phi), \\
\bar{\omega}_{\mathrm{e}}(\lambda)=\bar{\omega}_{\mathrm{i}}(\lambda) \frac{\overline{\mathrm{Q}}_{\mathrm{ext}, \mathrm{i}}(\lambda)}{\overline{\mathrm{Q}}_{\mathrm{e}, \mathrm{ext}}(\lambda)} \frac{\mathrm{D}_{\mathrm{e}}}{\mathrm{D}_{\mathrm{e}, \mathrm{i}}} \phi+\bar{\omega}_{\mathrm{w}}(\lambda) \frac{\overline{\mathrm{Q}}_{\mathrm{ext}, \mathrm{w}}(\lambda)}{\overline{\mathrm{Q}}_{\mathrm{e}, \mathrm{ext}}(\lambda)} \frac{\mathrm{D}_{\mathrm{e}}}{\mathrm{D}_{\mathrm{e}, \mathrm{w}}}(1-\phi), \\
\overline{\mathrm{p}}_{\mathrm{e}}(\theta, \lambda)=\overline{\mathrm{p}}_{\mathrm{i}}(\theta, \lambda) \frac{\overline{\mathrm{Q}}_{\mathrm{sca}, \mathrm{i}}}{\overline{\mathrm{Q}}_{\mathrm{e}, \mathrm{sca}}} \frac{\mathrm{D}_{\mathrm{e}}}{\mathrm{D}_{\mathrm{e}, \mathrm{i}}} \phi+\overline{\mathrm{p}}_{\mathrm{w}}(\theta, \lambda) \frac{\overline{\mathrm{Q}}_{\mathrm{sca}, \mathrm{w}}}{\overline{\mathrm{Q}}_{\mathrm{e}, \mathrm{sca}}} \frac{\mathrm{D}_{\mathrm{e}}}{\mathrm{D}_{\mathrm{e}, \mathrm{w}}}(1-\phi),
\end{gathered}
$$

where the first subscript e of $\bar{Q}_{e, e x t}(\lambda), \bar{Q}_{e, s c a}(\lambda), \bar{\omega}_{e}(\lambda), \bar{g}_{e}(\lambda)$, and $\bar{p}_{e}(\theta, \lambda)$ indicates the externally mixed model. $\phi$ is the volume fraction of ice in the mixed-phase cloud. $D_{e, i}$ and $D_{e, w}$ are the effective diameters of ice cloud and liquid water cloud, respectively. From the above formulation, the mixed-phase cloud properties can be derived using existing ice and liquid water cloud bulk optical properties [23].

In this study, the ice volume fraction $\phi$ is defined as:

$$
\phi=\frac{\int_{D_{\min }}^{D_{\max }} V_{i}(D) N_{i}(D) d D}{\int_{D_{\min }}^{D_{\max }} V_{i}(D) N_{i}(D) d D+\int_{D_{\min }}^{D_{\max }} V_{W}(D) N_{W}(D) d D}
$$

An important aspect of defining the mixed-phase cloud is how to distinguish the liquid phase, the mixed-phase, and the ice phase of the cloud according to the $\phi$ value. At present, there is no physical explanation for the selection of $\phi$ value. According to the study by Korolev et al. [8], $0 \leq \phi \leq 0.1$ corresponds to liquid phase, $0.1<\phi<0.9$ corresponds to mixed-phase, and $0.9 \leq \phi \leq 1$ corresponds to ice phase.

\section{Results and Discussions}

The sensitivity of mixed-phase cloud optical properties to various microphysical factors is analyzed in more details below. Note that the externally mixed case with spherical liquid water droplets and single column ice particles is selected to represent the externally mixed model in Section 3.1, Section 3.2, and Section 3.4.

\subsection{Effective Diameter}

Figure 1 shows the spectral characteristics of optical properties of externally and internally mixed models at various effective diameters with an ice volume fraction of 0.7 . The scattering properties calculated with the externally and internally mixed cloud models are generally comparable and similar trends of variation with effective particle sizes and wavelengths are found except that the latter exhibits stronger variations with wavelength. Similar to a previous study [23], larger particles typically exhibit smaller variations in optical properties across the spectrum. More sharper variations in extinction efficiency, scattering efficiency, and asymmetry factor are found at the near- to mid-infrared spectral regions of 3-20 $\mu \mathrm{m}$. Since the ice volume fraction is relatively high (0.7) in this case, the spectral features of ice can be clearly found. For example, a lower bulk extinction efficiency and single scattering albedo appear at the wavelength of $10 \mu \mathrm{m}$, which is referred to as the Christian effect [60]. The bulk asymmetry factors of externally and internally mixed cases are also similar, while the latter exhibits stronger sensitivity to effective particle size at the longwave region.

\subsection{Ice Volume Fraction}

The influence of ice volume fraction on the optical properties of the internally and externally mixed models are both examined in Figure 2, where the bulk optical properties across the spectrum are shown as the ice volume fraction varies. It is noted that the ice volume fractions induce different spectral signature changes of the bulk extinction and 
scattering efficiencies in the internally and externally mixed models. For the internally mixed model, the affected spectral region mainly resides in the mid- to far-infrared spectral regions. Meanwhile, for the externally mixed model, the optical properties in the visible and near-infrared regions are also significantly perturbed by the ice volume fraction. The extinction and scattering efficiencies mostly decrease as the ice volume fraction increases across the whole spectrum except that the variation trend reverses at the spectral window of $10-25 \mu \mathrm{m}$ and at a small window around $50 \mu \mathrm{m}$. However, both particle models show similar variations in single scattering albedo with respect to the ice volume fraction although the scattering and extinction efficiencies are perturbed differently. It can be seen that the variation of single scattering albedo associated with the ice volume fraction changes can be up to 0.3 at the wavelength around $23 \mu \mathrm{m}$.
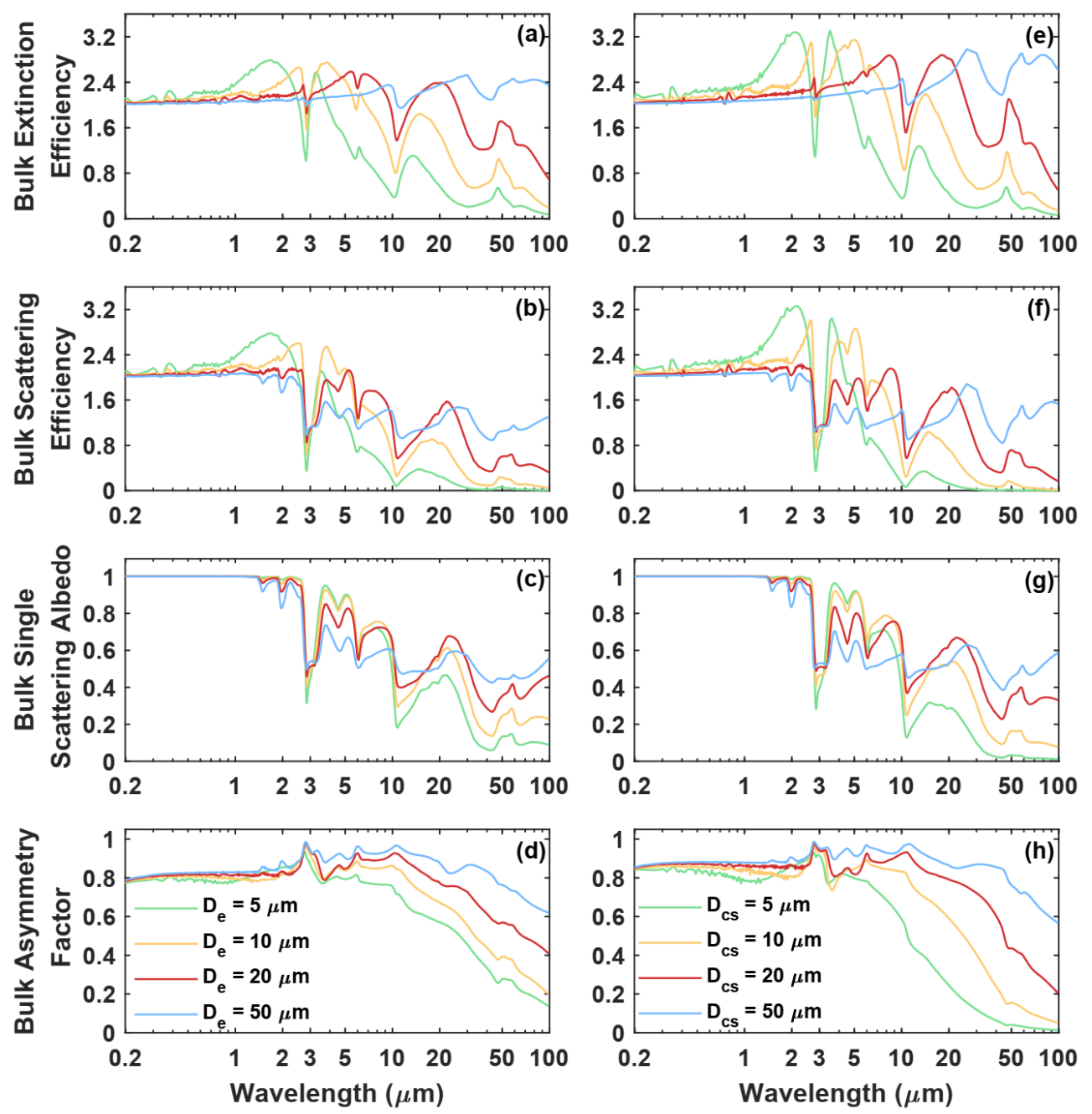

Figure 1. Variations in bulk optical properties of externally (left panels) and internally (right panels) mixed model over the spectrum at four representative effective diameters. (a,e) bulk extinction efficiency; (b,f) bulk scattering efficiency; $(\mathbf{c}, \mathbf{g})$ bulk single scattering albedo; $(\mathbf{d}, \mathbf{h})$ bulk asymmetry factor. The ice volume fraction is 0.7. For $\mathrm{D}_{\mathrm{e}}=5 \mu \mathrm{m}, \mathrm{D}_{\mathrm{e}, \mathrm{i}}=5.98 \mu \mathrm{m}, \mathrm{D}_{\mathrm{e}, \mathrm{w}}=3.55 \mu \mathrm{m} ;$ For $\mathrm{D}_{\mathrm{e}}=10 \mu \mathrm{m}$, $\mathrm{D}_{\mathrm{e}, \mathrm{i}}=12.56 \mu \mathrm{m}, \mathrm{D}_{\mathrm{e}, \mathrm{w}}=6.66 \mu \mathrm{m} ;$ For $\mathrm{D}_{\mathrm{e}}=20 \mu \mathrm{m}, \mathrm{D}_{\mathrm{e}, \mathrm{i}}=25.2 \mu \mathrm{m}, \mathrm{D}_{\mathrm{e}, \mathrm{w}}=13.38 \mu \mathrm{m} ;$ For $\mathrm{D}_{\mathrm{e}}=50 \mu \mathrm{m}$, $\mathrm{D}_{\mathrm{e}, \mathrm{i}}=62.6 \mu \mathrm{m}, \mathrm{D}_{\mathrm{e}, \mathrm{w}}=33.5 \mu \mathrm{m}$.

Different features of the asymmetry factor variation are identified for externally and internally mixed models. Larger ice volume fraction signifies smaller bulk asymmetry factor for the wavelengths below $3 \mu \mathrm{m}$, while the opposite is true for the wavelengths above $3 \mu \mathrm{m}$ for the externally mixed model. The internally mixed counterpart however shows 
much lower sensitivity to the ice volume fraction. The asymmetry factor of the externally mixed model of mixed-phase cloud is lower than that of liquid water cloud and is higher than that of ice cloud in the visible spectrum [10]. As is mentioned in a previous study, even with the inclusion of a small fraction of liquid water droplets, the optical properties of the mixed-phase cloud are quite different from those of pure ice clouds [23]. This feature can also be similarly found in both models, but more evident changes are found in the external model.
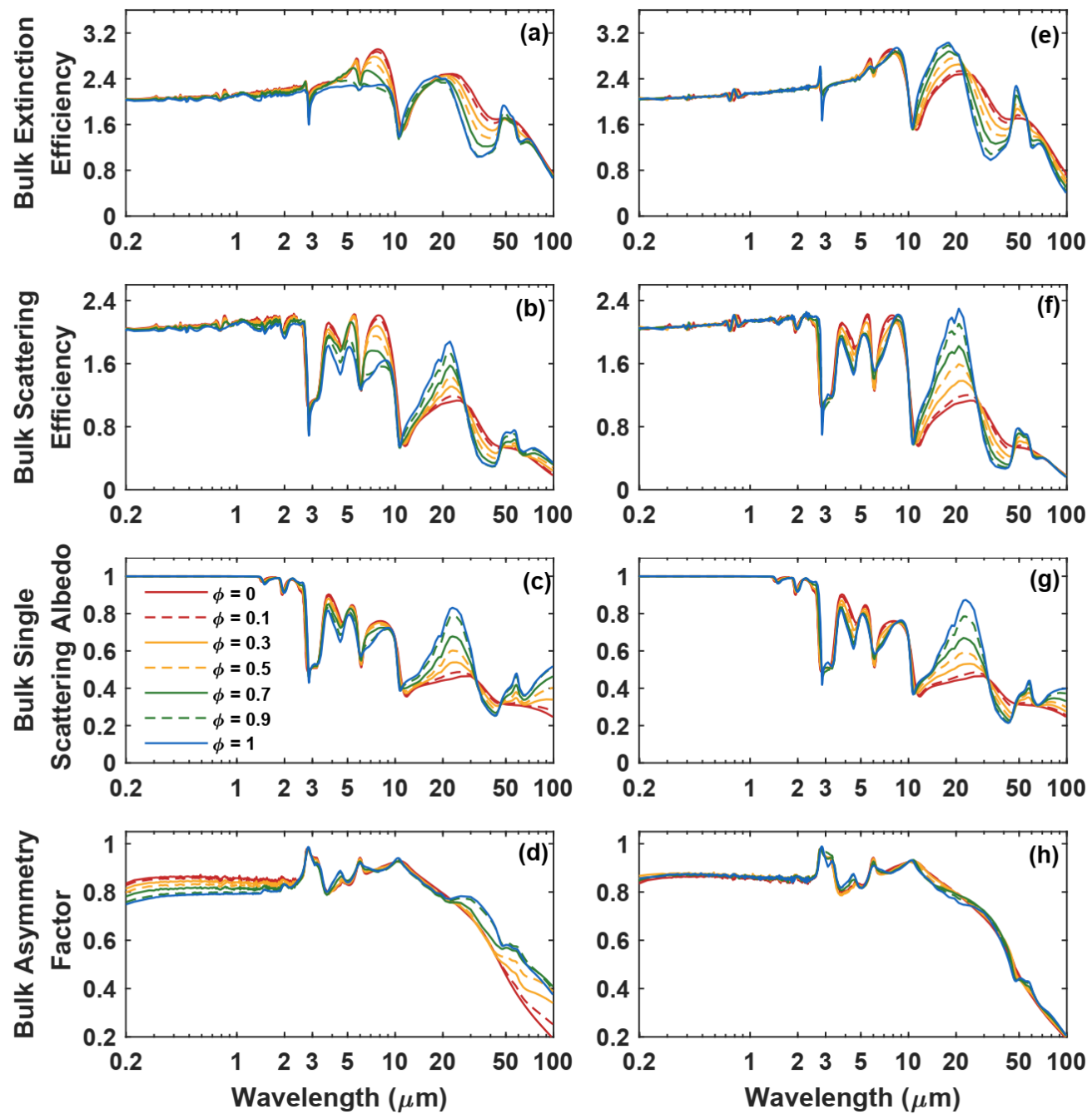

Figure 2. Variations in bulk optical properties of externally (left panels) and internally (right panels) mixed model over the spectrum at various ice volume fractions. (a,e) bulk extinction efficiency; $(\mathbf{b}, \mathbf{f})$ bulk scattering efficiency; (c,g) bulk single scattering albedo; $(\mathbf{d}, \mathbf{h})$ bulk asymmetry factor. $\mathrm{D}_{\mathrm{cs}}=20 \mu \mathrm{m}, \mathrm{D}_{\mathrm{e}}=20 \mu \mathrm{m}$, and $\phi=0,0.1,0.3,0.5,0.7,0.9,1.0$. When $\phi=0.1, \mathrm{D}_{\mathrm{e}, \mathrm{i}}=27.2 \mu \mathrm{m}$, $\mathrm{D}_{\mathrm{e}, \mathrm{w}}=19.3 \mu \mathrm{m}$; When $\phi=0.3, \mathrm{D}_{\mathrm{e}, \mathrm{i}}=27.5 \mu \mathrm{m}, \mathrm{D}_{\mathrm{e}, \mathrm{w}}=17.8 \mu \mathrm{m}$; When $\phi=0.5, \mathrm{D}_{\mathrm{e}, \mathrm{i}}=26.6 \mu \mathrm{m}$, $\mathrm{D}_{\mathrm{e}, \mathrm{w}}=16 \mu \mathrm{m}$; When $\phi=0.7, \mathrm{D}_{\mathrm{e}, \mathrm{i}}=25.2 \mu \mathrm{m}, \mathrm{D}_{\mathrm{e}, \mathrm{w}}=13.4 \mu \mathrm{m}$; When $\phi=0.9, \mathrm{D}_{\mathrm{e}, \mathrm{i}}=22.6 \mu \mathrm{m}$, $\mathrm{D}_{\mathrm{e}, \mathrm{w}}=9.2 \mu \mathrm{m}$.

When the externally and internally mixed models are compared in Figure 2, it should be noted that the impacts of ice particle shape on the cloud properties become more obvious as the ice volume fraction increases. When the ice volume fraction reaches 1 , it is the single column ice particle and spherical ice particle that are compared. The detail analysis of the influence of ice crystal shape is given in Section 3.3.

Figure 3 shows the bulk scattering phase functions of the internally and externally mixed models with different ice volume fractions at the wavelength of $8 \mu \mathrm{m}$. In the 
internally mixed model, the ice volume fraction has little effect on the forward scattering phase function while stronger backscattering is found for higher ice volume fraction case. However, in the externally mixed model, the forward and backward scattering peaks are both stronger when the ice volume fraction increases. It is found that the variations in scattering phase functions with ice volume fraction changes correspond well with those of the bulk asymmetry factor (Figure $2 \mathrm{~d}, \mathrm{~h}$ ) at the other wavelengths (figures not shown).
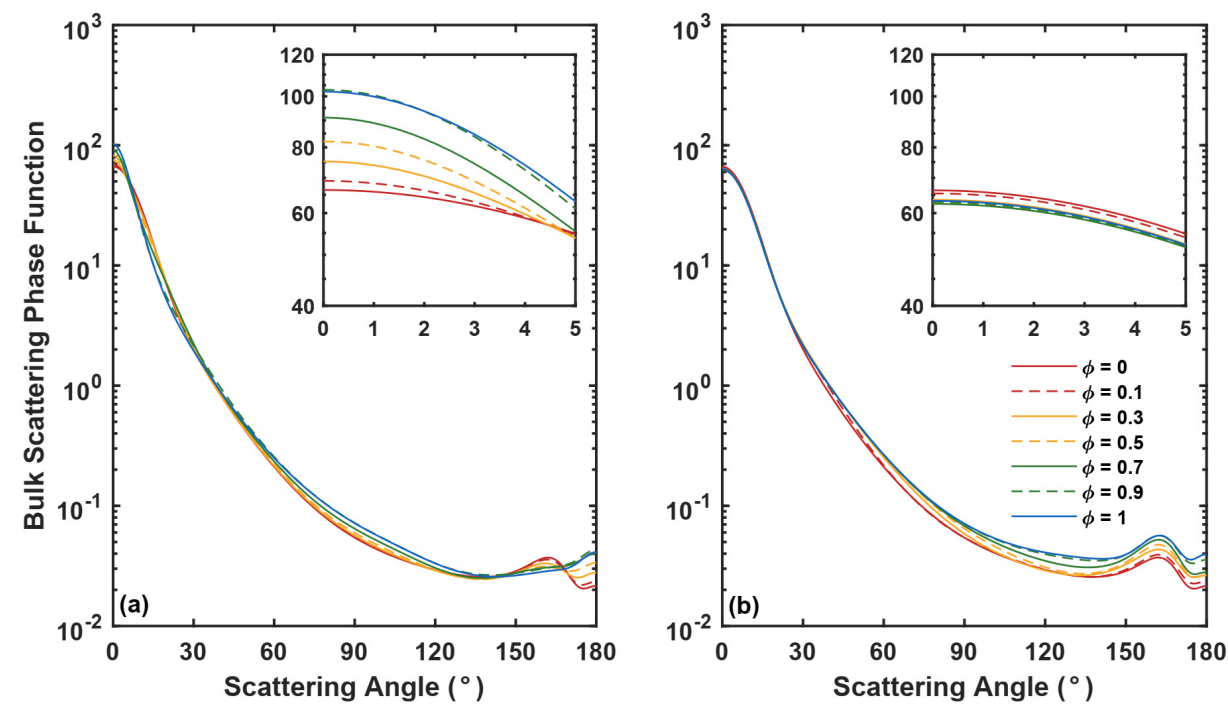

Figure 3. Bulk scattering phase function of (a) externally and (b) internally mixed models for scattering angles between $0^{\circ}$ and $180^{\circ}$ at the wavelength of $8 \mu \mathrm{m}$ where $D_{c s}=20$ and $D_{e}=20 \mu \mathrm{m}$. The $D_{e, i}$ and $D_{e, w}$ corresponding to each $\phi$ value are the same as those described in the caption of Figure 2.

\subsection{Shapes of Ice Crystals}

Since the optical properties of ice crystals with different shapes can be remarkably different, the ice crystal habits in the mixed-phase cloud are also found to be an important modulator of mixed-phase cloud optical properties [25]. Nine ice crystal habits from a comprehensive ice optical property database [36,54] were selected to study the influence of ice morphology on the optical properties of the externally mixed-phase cloud. Figure 4 shows the bulk extinction efficiency, scattering efficiency, single scattering albedo, and asymmetry factor of the externally mixed model consisting of ice crystals with different shapes and spherical liquid water droplets in the $0.2-100 \mu \mathrm{m}$ spectral range. The optical properties of mixed-phase clouds in the whole spectrum are obviously affected by the shapes of ice crystals except for a few strong absorbing bands such as 3 and $10 \mu \mathrm{m}$. Although the bulk extinction efficiency and scattering efficiency are different for various ice crystal shapes, Figure 4c shows that the bulk single scattering albedo is mostly not affected by the shapes of ice crystal in the shortwave to near-infrared spectral range. Contrary to the extinction and scattering efficiencies, more apparent changes in the single-scattering albedo are found at longer wavelengths $(>50 \mu \mathrm{m})$. The bulk asymmetry factor in the whole spectral range is sensitive to the ice crystal shapes except for the wavelengths around $3 \mu \mathrm{m}$. The externally mixed model with the inclusion of ice plate aggregates (5-plate and 10-plate) exhibits the largest asymmetry factor while the counterparts with inclusion of column aggregate (8-column) and droxtal show the lowest asymmetry factors in the visible to near-infrared and mid- to far-infrared regions, respectively. This feature is consistent with the results found for pure ice crystals [36]. 

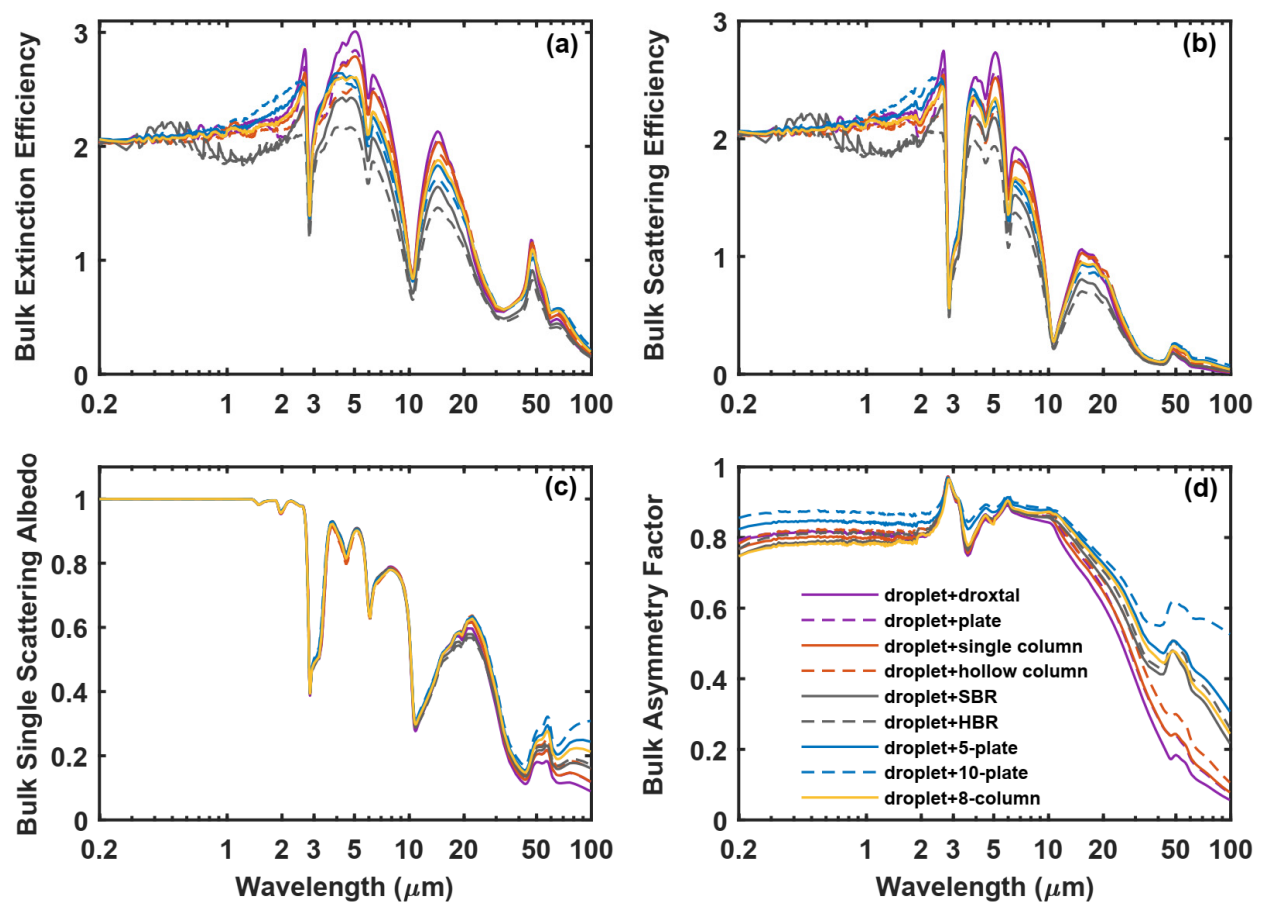

Figure 4. Bulk optical properties of the externally mixed model with nine different ice crystal habits: (a) bulk extinction efficiency; (b) bulk scattering efficiency; (c) bulk single scattering albedo; (d) bulk asymmetry factor, where the effective diameters of ice crystal $\left(D_{e, i}\right)$ and liquid droplet $\left(D_{e, w}\right)$ are both $10 \mu \mathrm{m}$. The ice volume fraction is 0.7 .

The influence of ice crystal shapes also varies with the effective particle diameter. Figure 5 shows the optical properties as a function of the effective diameter for the externally mixed model assuming different ice crystal shapes at the wavelength of $8 \mu \mathrm{m}$. It can be seen that the ice shape effect is most prominent when the effective diameters are relatively small. When the mixed-phase cloud effective sizes are sufficiently large, the ice shape impacts gradually diminish. For the case shown in Figure 5, the mixture of spherical water droplets and droxtal ice particles has the largest bulk extinction efficiency and scattering efficiency when the effective particle diameter is within 5-20 $\mu \mathrm{m}$. In contrast, the mixture of spherical liquid water droplets and HBR ice particles has the smallest bulk extinction efficiency and scattering efficiency. As a result of the changes in scattering and extinction efficiencies, the impacts of ice habit on bulk single scattering albedo are more evident at the effective diameter range of 15-35 $\mu \mathrm{m}$ (Figure $5 \mathrm{c}$ ). The bulk asymmetry factor is lowest for the mixture containing droxtal and is highest for the mixture containing 10-plate aggregate. As the effective particle diameter of mixed-phase cloud increases to about $15 \mu \mathrm{m}$, the bulk extinction efficiency and scattering efficiency of the mixed-phase cloud exhibit the largest influence by ice crystal shape. However, the impact of ice habit on asymmetry factor is largest at the lowest effective diameter and gradually reduces when the effective diameter increases. When the effective particle diameter increases to more than $35 \mu \mathrm{m}$, the effect of ice crystal shape on the mixed-phase cloud optical properties become negligible. Note the above analysis and results may be different when the wavelength of interest is changed.

\subsection{Mixture Models}

To illustrate the rationality of the internally mixed model for simulating the optical properties of the mixed-phase cloud, the internally and externally mixed models are thoroughly compared. As different definitions of effective diameters are used for externally and internally mixed-phase cloud models, we carry out the comparison by considering equal ice volume in externally and internally mixed cases. For the externally mixed model, 
the mixture case with ice column particle is considered as the control case to facilitate comparisons with previous studies.
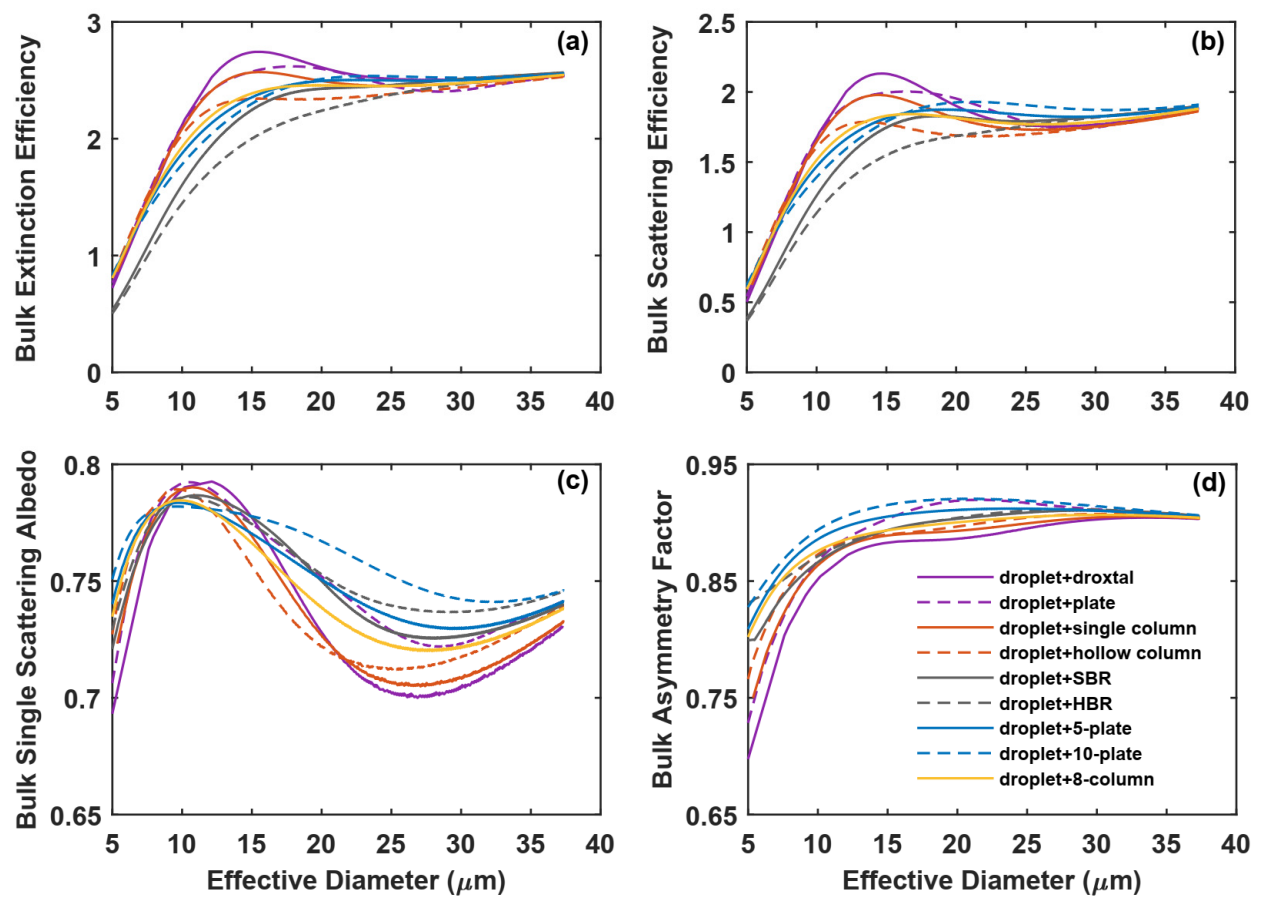

Figure 5. Bulk optical properties of the externally mixed model with nine different ice crystal habits at the wavelength of $8 \mu \mathrm{m}$ as a function of the effective diameter, where the effective diameter of ice crystal $\left(D_{e, i}\right)$ varies from 5 to $100 \mu \mathrm{m}$ and the effective diameter of liquid water $\left(D_{e, w}\right)$ is fixed at $15 \mu \mathrm{m}$ : (a) bulk extinction efficiency; (b) bulk scattering efficiency; (c) bulk single scattering albedo; and (d) bulk asymmetry factor. The ice volume fraction is 0.7 .

Figure 6 shows the comparison of optical properties of the internally mixed model with those of the externally mixed model in the spectral range of $0.2-100 \mu \mathrm{m}$. In the 0.2-60 $\mu \mathrm{m}$ spectral region, the bulk extinction efficiency and scattering efficiency of the internally mixed model are apparently greater than those of the external model, while the single scattering albedo in the internal case is basically lower. The bulk asymmetry factors of the internally mixed model are slightly larger than those of the external model in the $0.2-3 \mu \mathrm{m}$ spectral region, while the reverse is true for the $3-100 \mu \mathrm{m}$ range.

Figure 7 shows the bulk optical properties of the internally and externally mixed models as a function of ice volume fraction for mixed-phase cloud effective diameter of $15 \mu \mathrm{m}$ at the wavelength of $1.6 \mu \mathrm{m}$. With the increase of ice volume fraction, the volume of liquid water droplets decreases while the volume of ice crystals increases. Thus, the effect of ice crystal shape on the bulk extinction efficiency, scattering efficiency, and asymmetry factor of the mixed-phase cloud particles becomes more obvious as the ice volume fraction increases. The bulk extinction efficiency and bulk scattering efficiency of the internally mixed model are the largest among those of the externally mixed model, but they exhibit little sensitivities to the ice volume fraction. A slight decrease in bulk single scattering albedo with the increase of ice volume fraction is similarly found for both internally and externally mixed models. However, the bulk asymmetry factor shows very different trends of variation with respect to the ice volume fraction depending on the shape of ice crystals. External mixtures containing 10-plate and 5-plate aggregates of ice crystals both exhibit an increase of asymmetry factor as the ice volume fraction increases. Almost no change of asymmetry factor is found for the internal mixture as well as for the externally mixed case including ice plates. The other external mixture cases all show a decreasing trend of asymmetry factor with the increase of ice volume fraction. From the above comparison, it is found that the key optical properties of the internally mixed model mostly fall within 
the uncertainty range of the counterparts induced by ice crystal shapes in the externally mixed model.
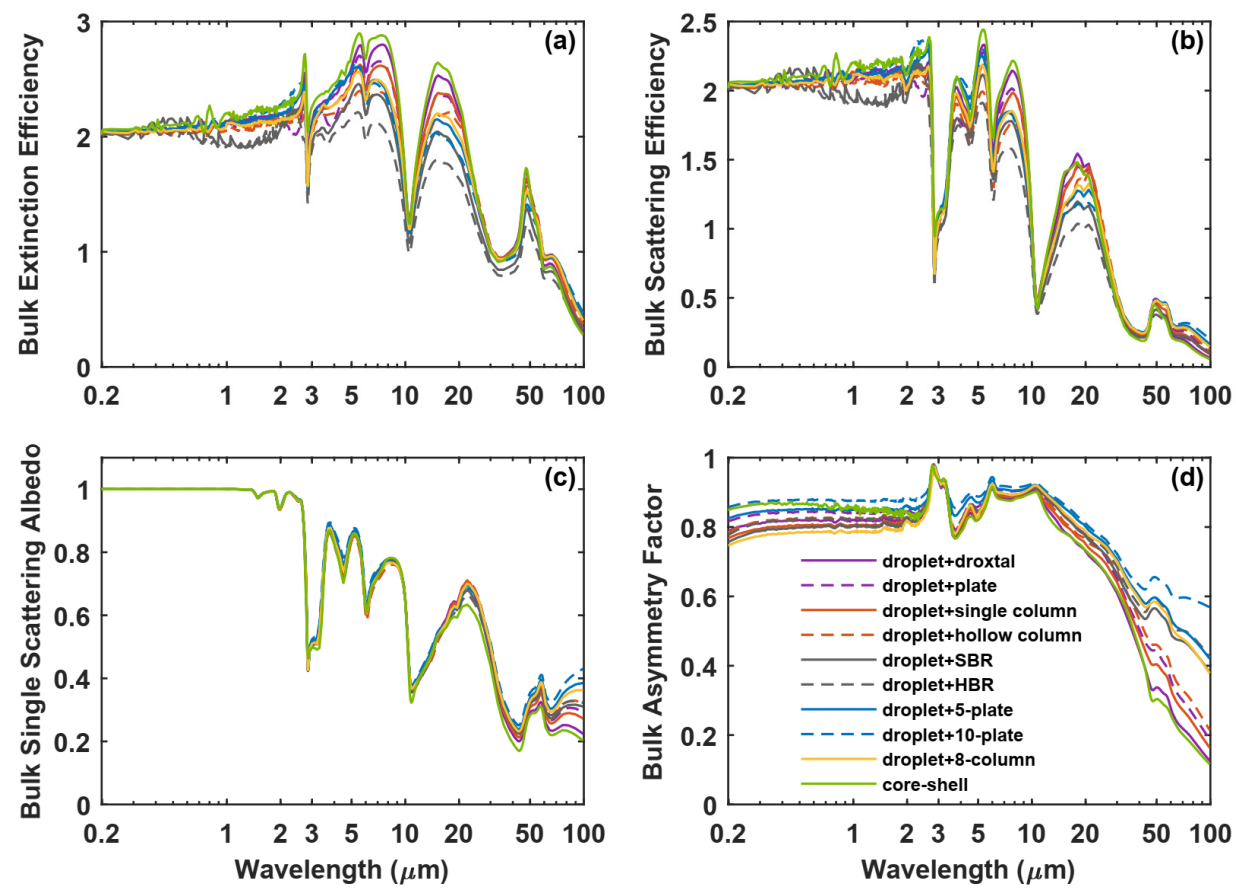

Figure 6. Comparison of the optical properties of externally and internally mixed model across the spectrum where the effective diameter of internally and externally mixed model is $15 \mu \mathrm{m}$ : (a) bulk extinction efficiency; (b) bulk scattering efficiency; (c) bulk single scattering albedo; (d) bulk asymmetry factor. The ice volume fraction is 0.7 . $\mathrm{D}_{\mathrm{e}, \mathrm{i}}=15 \mu \mathrm{m}$ and $\mathrm{D}_{\mathrm{e}, \mathrm{w}}=15 \mu \mathrm{m}$.
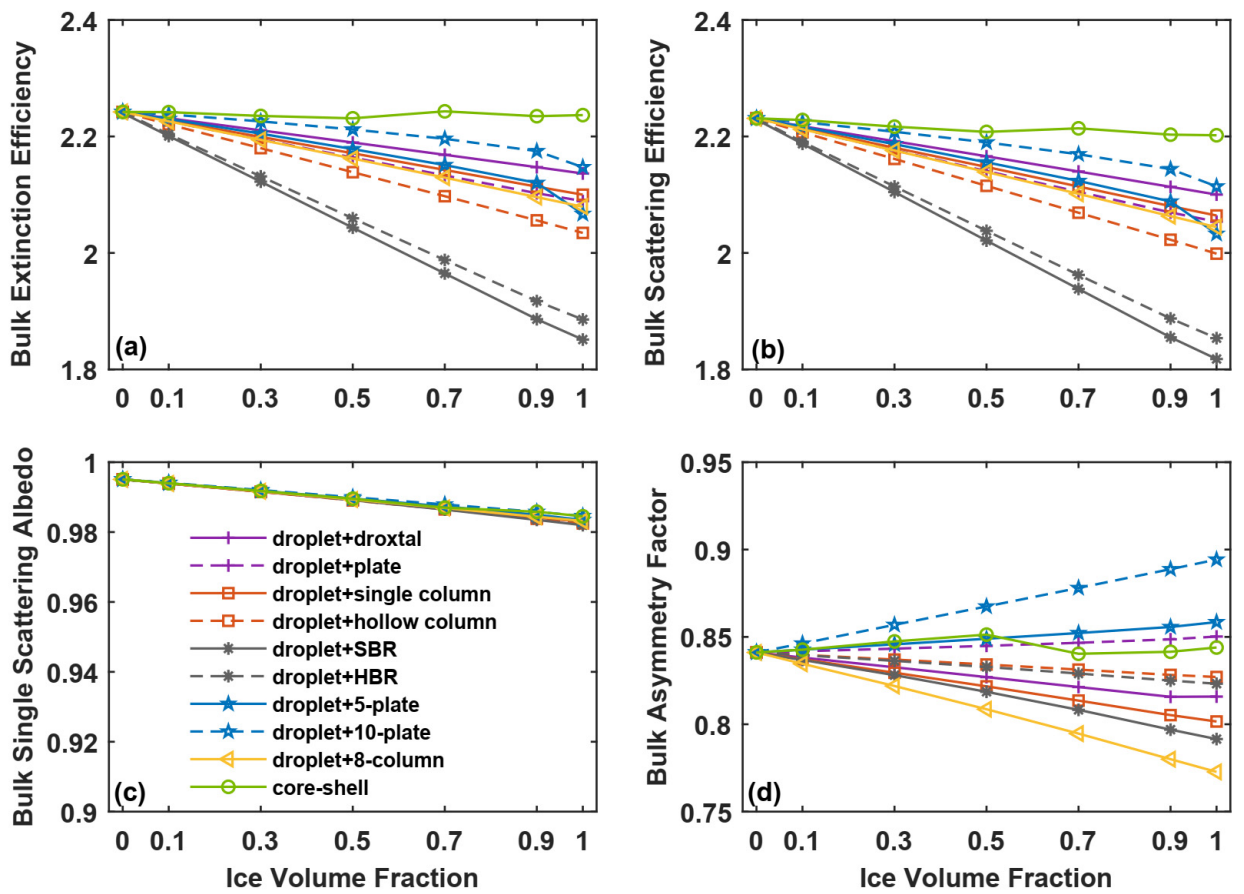

Figure 7. Variation of optical properties of externally and internally mixed model with ice volume fraction where the effective diameter is $15 \mu \mathrm{m}$ at the wavelength of $1.6 \mu \mathrm{m}$ : (a) bulk extinction efficiency; (b) bulk scattering efficiency; (c) bulk single scattering albedo; (d) bulk asymmetry factor. $\mathrm{D}_{\mathrm{e}, \mathrm{i}}=15 \mu \mathrm{m}$ and $\mathrm{D}_{\mathrm{e}, \mathrm{w}}=15 \mu \mathrm{m}$. 
Different from the ice clouds and liquid water clouds, the optical properties of mixedphase cloud particles may not be regarded as only a function of effective particle size [23]. The variation of optical properties of mixed-phase cloud in different spectral regions is complex and is under the influences of effective particle size and ice volume fraction. We further investigate the optical properties of mixed-phase cloud under the internally and externally mixed assumptions at four representative wavelengths.

Figures 8-11 show the optical properties as functions of effective particle size and ice volume fraction for externally and internally mixed models as well as the difference between them at various wavelength. At the wavelength of $0.65 \mu \mathrm{m}$, very different trends of variation are found for internally and externally mixed cloud properties (Figure 8). Comparatively, the internally mixed model is much less sensitive to the ice volume fraction and the scattering and extinction efficiencies are more dependent on the effective particle size. As a result, the corresponding differences between external and internal models are most prominent when the effective particle size is small, and gradually decrease as the effective diameter increases. The bulk single scattering albedo is not affected by the effective particle size, ice volume fraction, and mixing model, and maintains a constant value of 1 at the shortwave region. For asymmetry factor, ice volume fraction and effective diameter are equally important for the external model but not for the internal model. The differences in asymmetry factor between the two models show apparent relationship with the ice volume fraction (Figure 81).
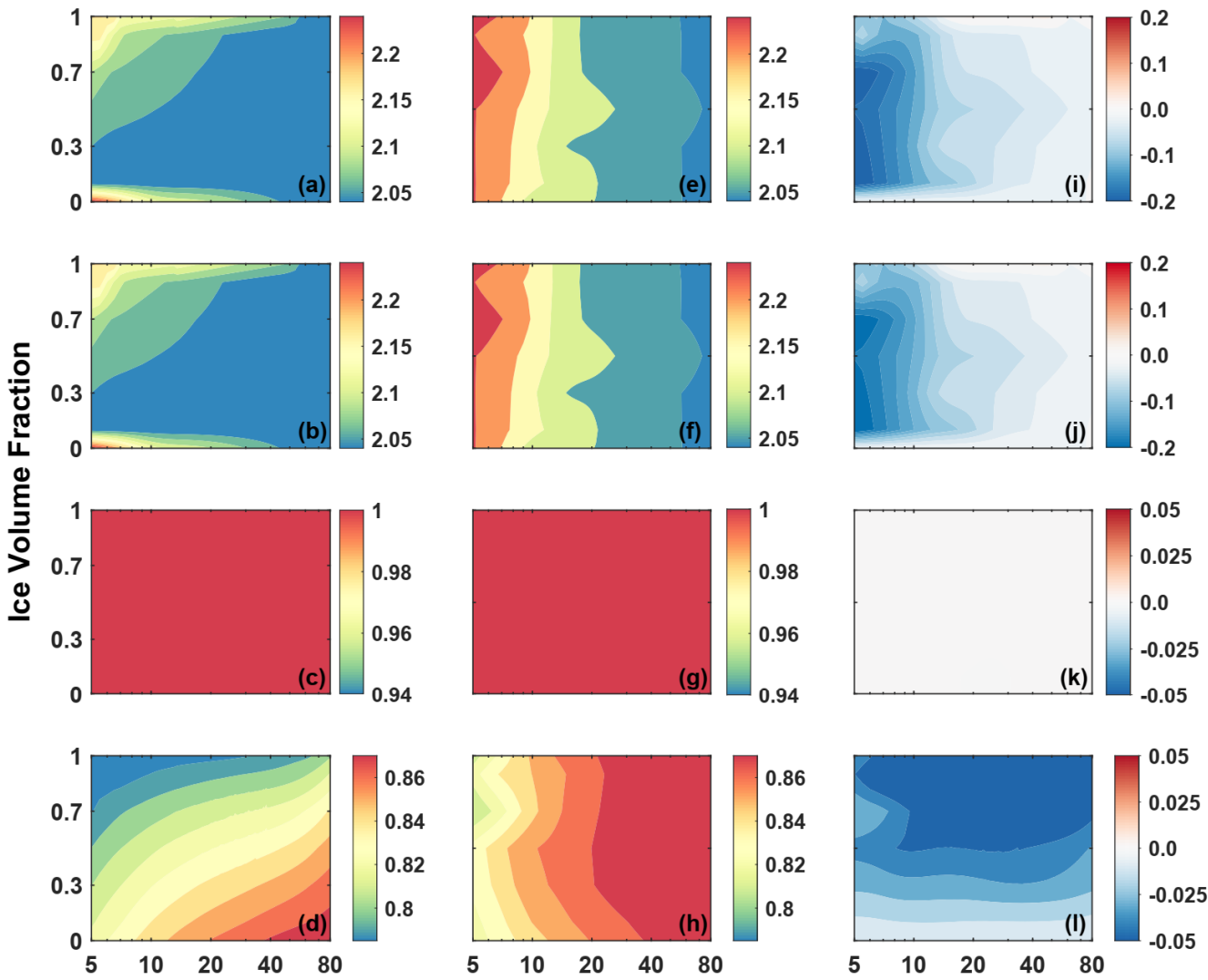

Effective Diameter $(\mu \mathrm{m})$

Figure 8. Bulk optical properties of externally (left panels) and internally (middle panels) mixed model and their differences (externally minus internally mixed model) (right panels) as functions of effective particle diameter and ice volume fraction at the wavelength of $0.65 \mu \mathrm{m}$ : (a,e,i) bulk extinction efficiency; $(\mathbf{b}, \mathbf{f}, \mathbf{j})$ bulk scattering efficiency; $(\mathbf{c}, \mathbf{g}, \mathbf{k})$ bulk single scattering albedo; $(\mathbf{d}, \mathbf{h}, \mathbf{l})$ bulk asymmetry factor. 

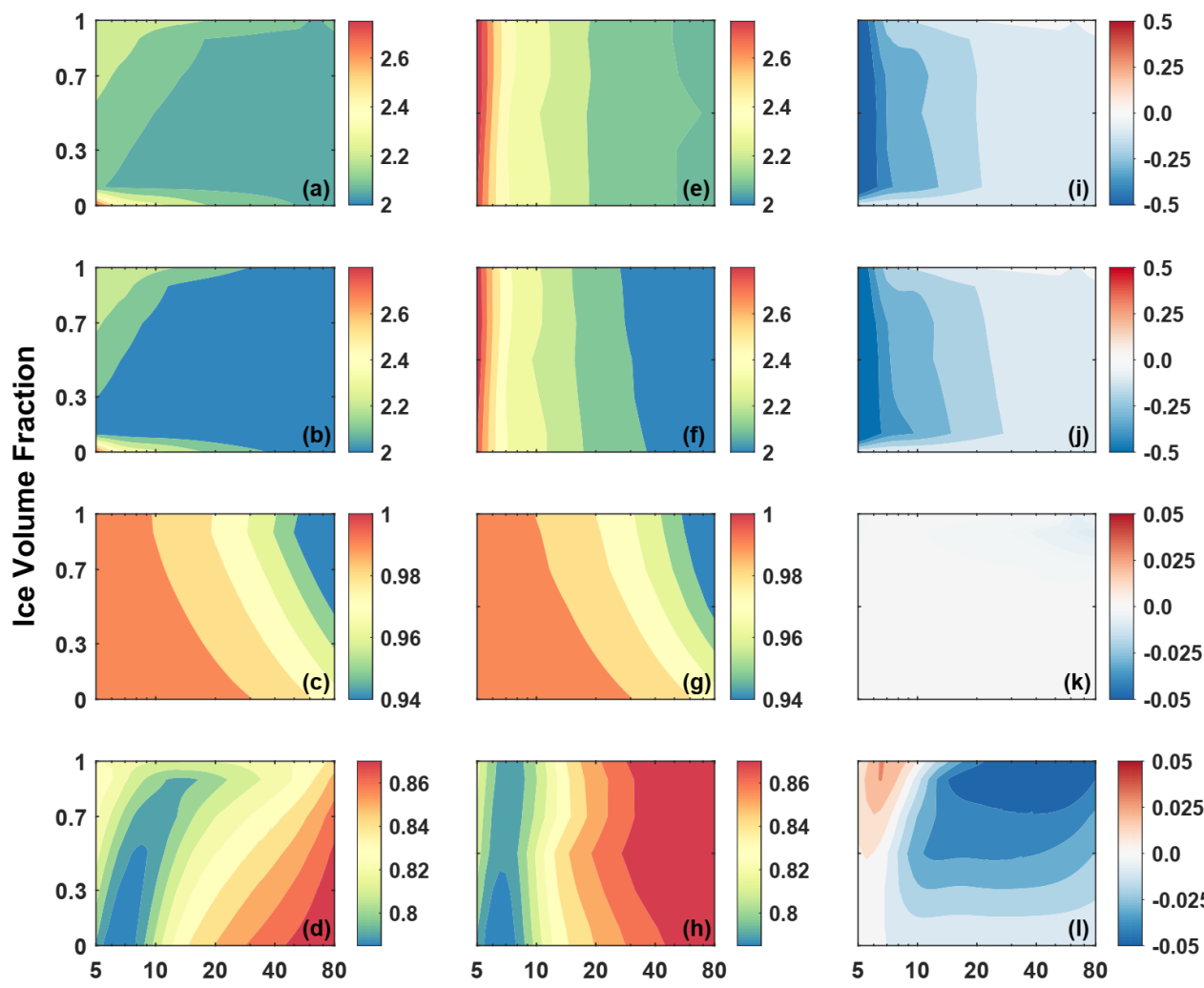

Effective Diameter $(\mu \mathrm{m})$

Figure 9. Same as Figure 8, but for the wavelength of $1.6 \mu \mathrm{m}$.
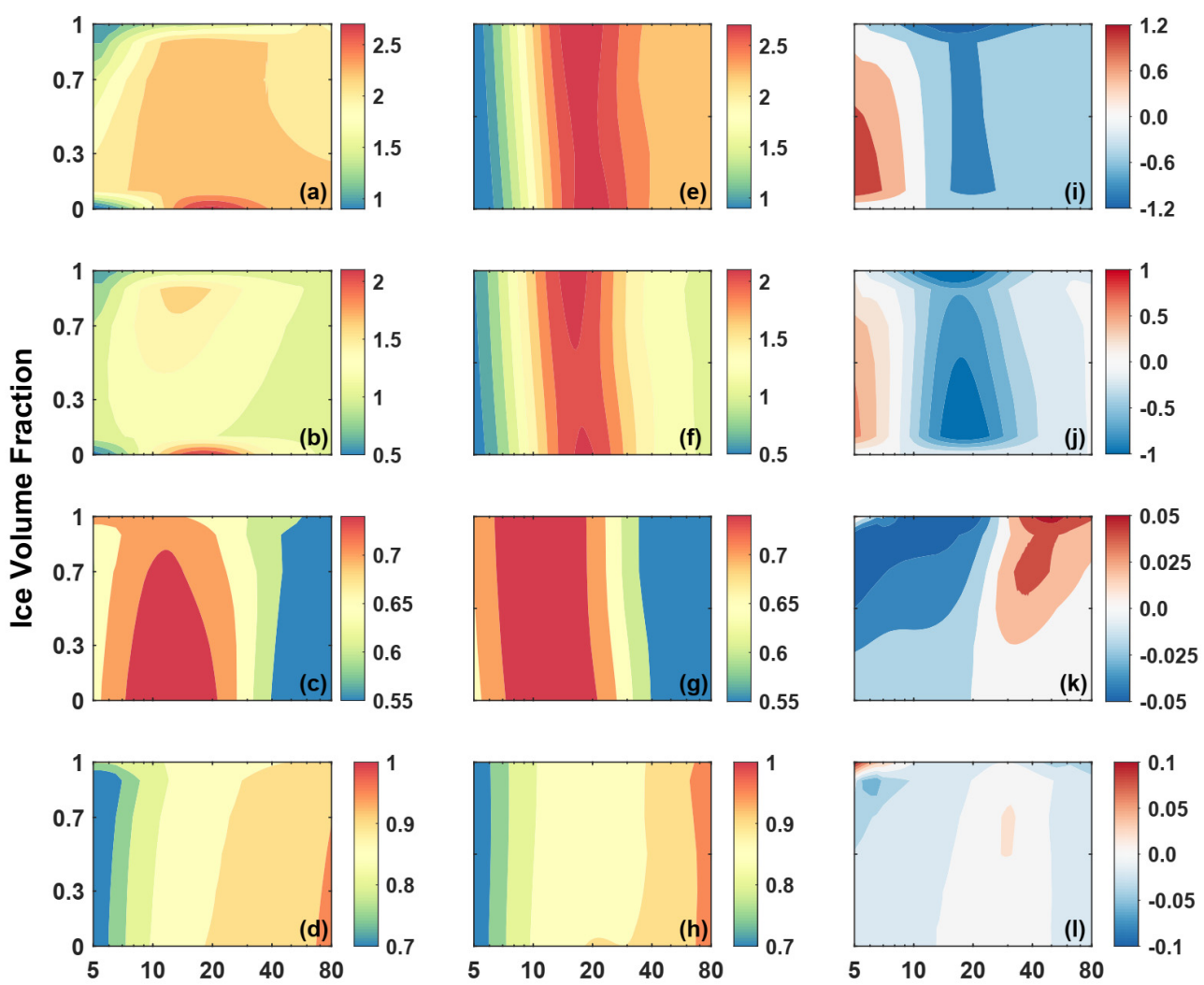

Effective Diameter $(\mu \mathrm{m})$

Figure 10. Same as Figure 8, but for the wavelength of $8 \mu \mathrm{m}$. 

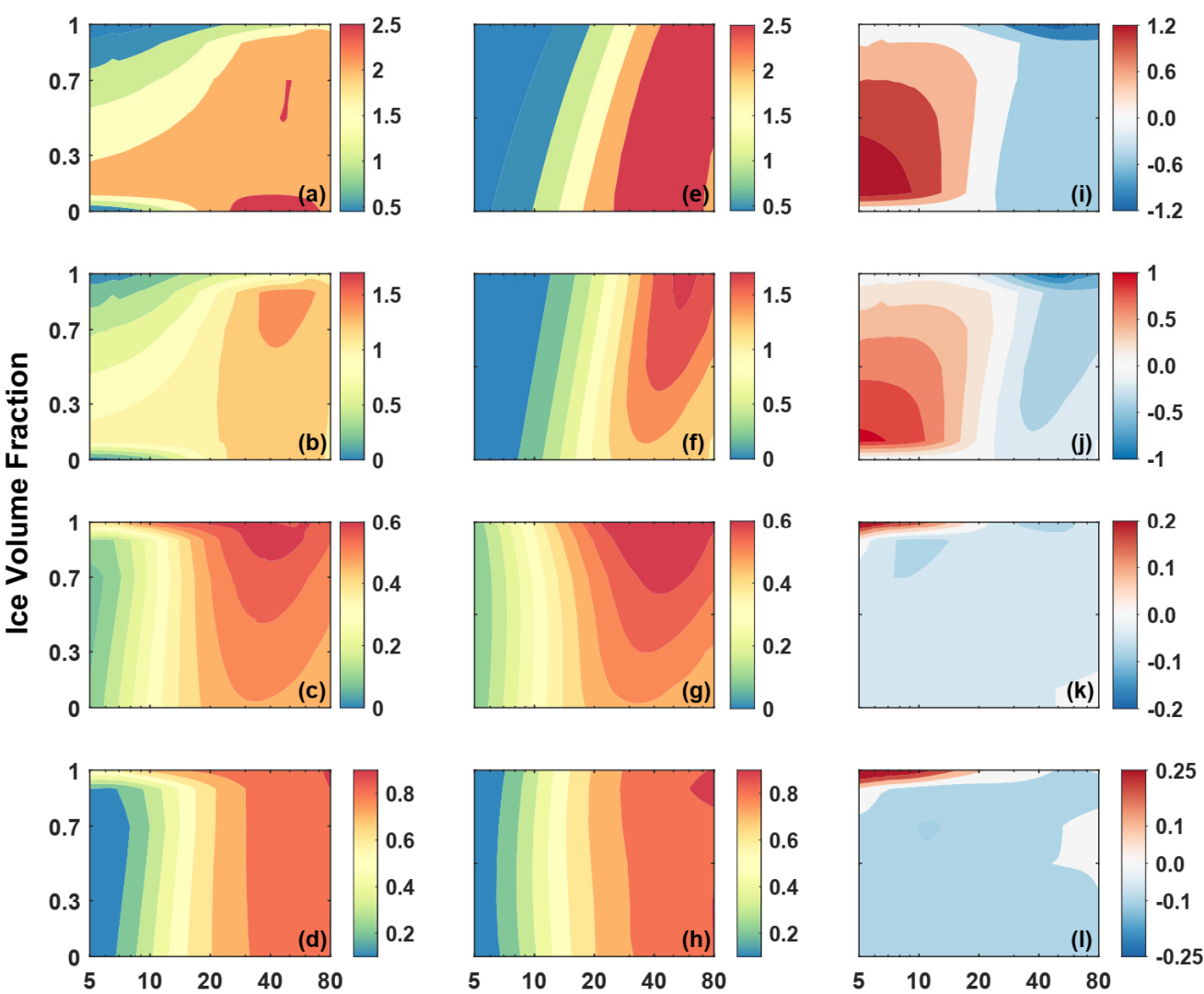

Effective Diameter $(\mu \mathrm{m})$

Figure 11. Same as Figure 8, but for the wavelength of $30 \mu \mathrm{m}$.

At the wavelength of $1.6 \mu \mathrm{m}$ in the near-infrared region, the bulk extinction efficiency and scattering efficiency of both mixed-phase cloud particle models mostly follow the same trend of variation with effective particle diameter and ice volume fraction as those of the visible part (Figure 9). With the increase in effective particle diameter, the bulk single scattering albedo slightly decreases. The asymmetry factor similarly increases as the effective diameter $(>10 \mu \mathrm{m})$ increases for both internally and externally mixed cases, while the increasing ice volume fraction brings about stronger impacts for the externally mixed cases than for the internally mixed cases.

At the wavelength of $8 \mu \mathrm{m}$ in the infrared region, the differences in extinction and scattering efficiencies between the two mixed models become larger (Figure 10). With the increase in absorption of ice and liquid water, the single scattering albedo significantly changes with effective particle diameter where the differences between the two mixed cloud models also become larger. It is interesting to find that the trend of variation of asymmetry factor in both mixed-phase cloud models becomes less sensitive to the ice volume fraction in the infrared region.

As the wavelength increases to $30 \mu \mathrm{m}$, the difference of bulk extinction and scattering efficiencies between internally and externally mixed models increases (Figure 11). The single scattering albedo of mixed-phase clouds with smaller effective diameters $(<20 \mu \mathrm{m})$ have little sensitivity to ice volume fraction, while the single scattering albedo increases remarkably as the ice volume fraction increases for larger sizes $(>20 \mu \mathrm{m})$. Compared with the other cases at the shorter wavelengths, the asymmetry factor also tends to vary only with effective particle diameter.

As a brief summary, the internally and externally mixed cloud models show different trends of variations in bulk optical properties with effective particle diameters and ice volume fractions at various wavelengths. The differences of bulk extinction efficiency and scattering efficiency between the two mixed-phase cloud models grow larger as the 
wavelengths increase from visible and near-infrared to the mid- and far-infrared. Unlike the internally mixed model which constantly shows less sensitivity to ice volume fraction, the externally mixed model exhibits strong modulation of optical properties by the ice volume fraction. It is important that the bulk optical properties should be sufficiently examined before either mixed-phase cloud model is applied.

Figures 12 and 13 show the bulk scattering phase function for the internally and externally mixed models at the wavelengths of 8 and $0.65 \mu \mathrm{m}$, respectively. The bulk scattering phase function of the internally mixed model in the forward direction is lower than those of the external mixtures while having stronger side and back scattering. Overall, the phase function is close to those of the external mixture consisting of spherical water droplets and single hexagonal column ice crystals at the wavelength of $8 \mu \mathrm{m}$ (Figure 12). Comparatively, more apparent differences in the side scattering directions are discerned at the wavelength of $0.65 \mu \mathrm{m}$ (Figure 13). For the externally mixed cases, the forward scattering peaks are related with the shape of ice crystals, where the case consisting of 10plate ice aggregates and liquid water droplets has the largest forward scattering. Compared with the results in the shortwave spectral region, the side scattering and backscattering calculated in the infrared spectral region are essentially featureless, which is caused by the strong ice absorption in the infrared spectral region [35]. The side scattering and backscattering of the internal model are very close to those of the externally mixed model at the mid-infrared wavelength. In the shortwave spectral region, the forward scattering peak of the mixed-phase cloud particle is stronger, and the difference in the bulk scattering phase function between the internally and externally mixed models well reflects the contribution of particle morphology (Figure 13).

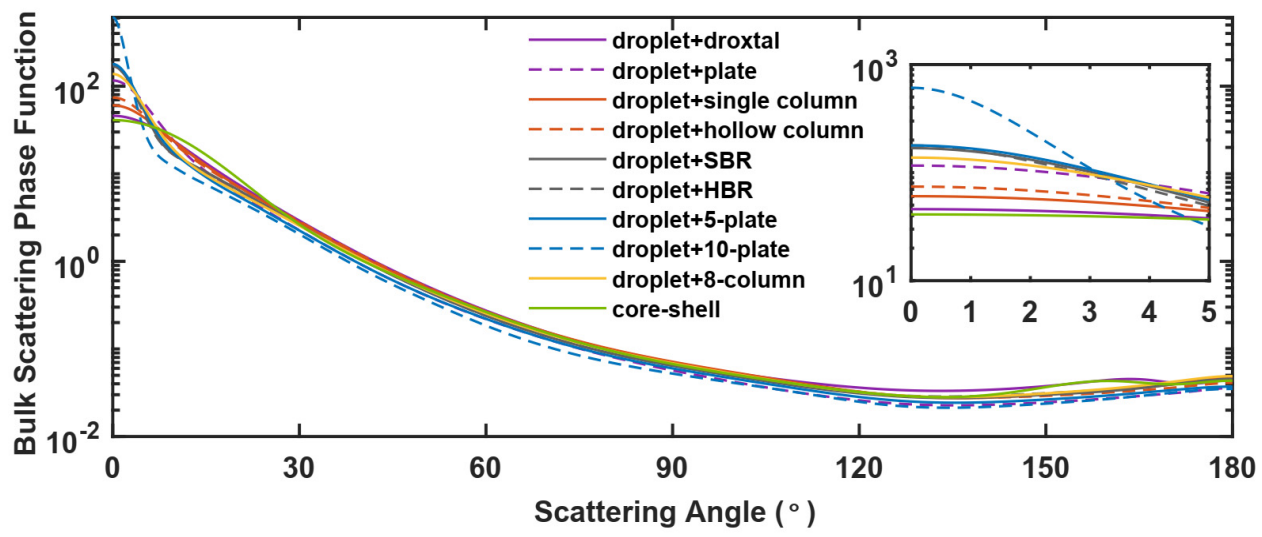

Figure 12. Comparison of the bulk scattering phase function of internally and externally mixed model with effective diameter of $15 \mu \mathrm{m}$ at the wavelength of $8 \mu \mathrm{m}$ where the ice volume fraction is 0.7. $\mathrm{D}_{\mathrm{e}, \mathrm{i}}=18.8 \mu \mathrm{m}$ and $\mathrm{D}_{\mathrm{e}, \mathrm{w}}=10 \mu \mathrm{m}$.

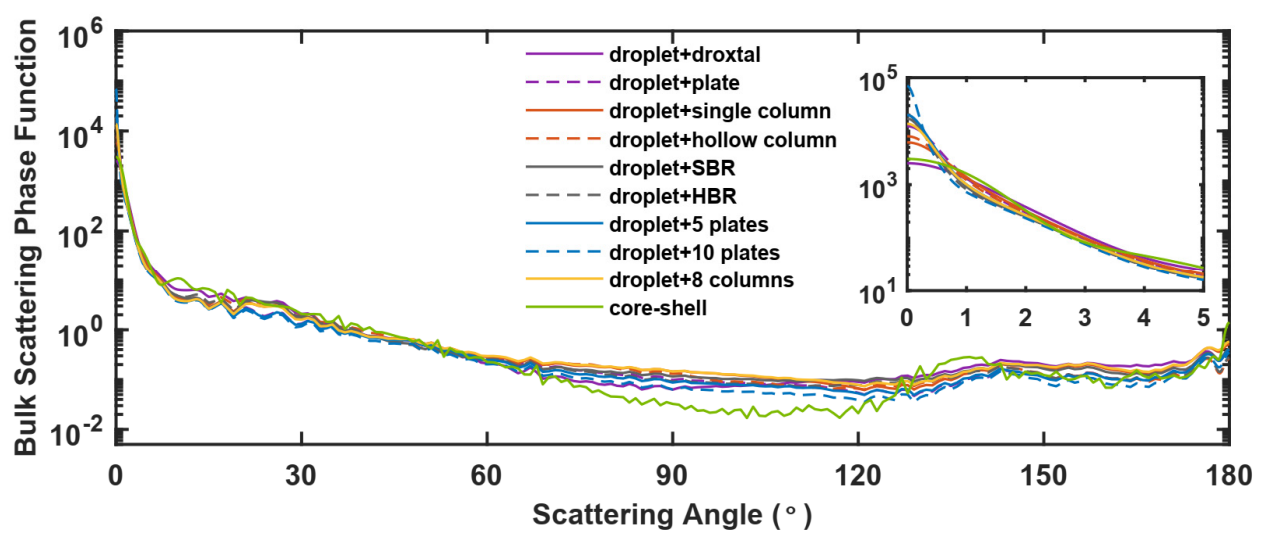

Figure 13. Same as Figure 12, but for the wavelength of $0.65 \mu \mathrm{m}$. 
We further examine a case where spherical liquid water droplet, single hexagonal column ice crystal, and the coated sphere cloud model co-exist (referred as co-exist model) to illustrate the influence of external and internal mixing. The equations to derive the optical properties of the co-exist model are given in Appendix B. Figures 14 and 15 show the bulk optical properties and scattering phase function of the internally mixed model, the externally mixed model, and the co-exist model, respectively. In the co-exist model case, the volume ratios of the spherical water droplet, single column ice crystal, and coated sphere model are designated as $15 \%, 35 \%$, and 50\%, respectively. The optical properties and scattering phase function of the co-exist mixed-phase cloud model fall within the range of the internally and externally mixed models. This example illustrates the possibility of considering complex mixing conditions within mixed-phase cloud.
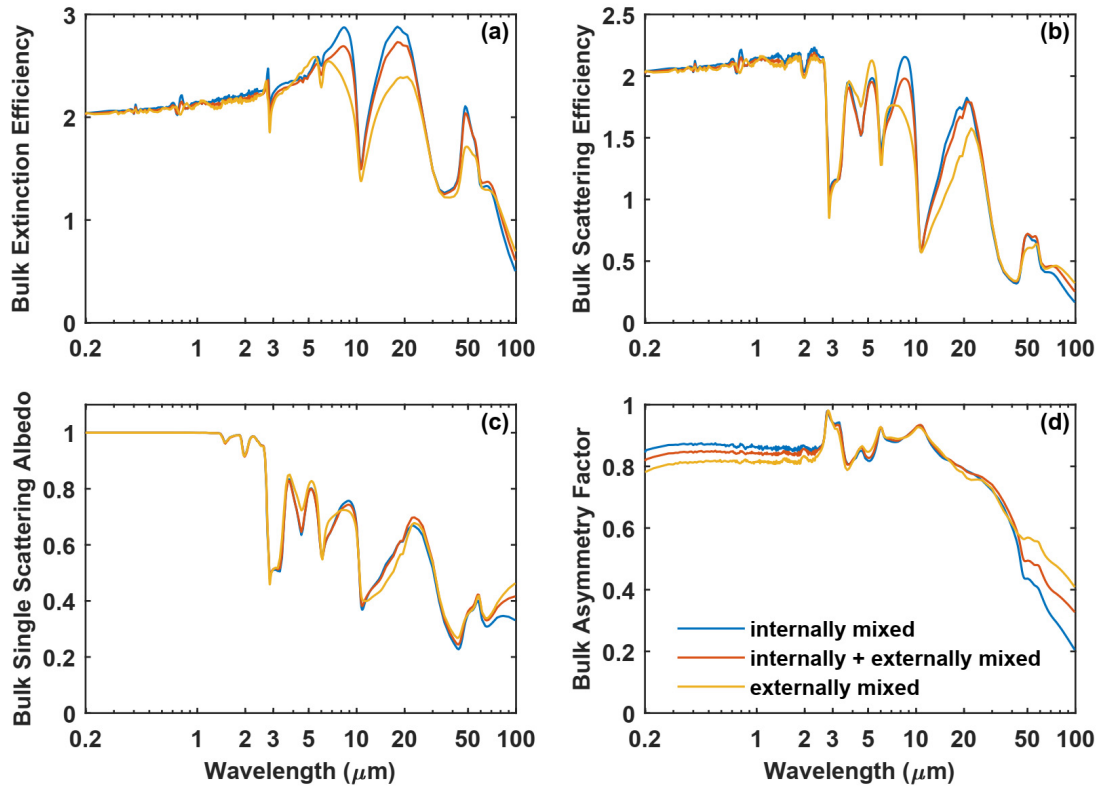

Figure 14. Variations in bulk optical properties of three mixed models over the spectrum from 0.2 to $100 \mu \mathrm{m}$ : (a) bulk extinction efficiency; (b) bulk scattering efficiency; (c) bulk single scattering albedo; (d) bulk asymmetry factor. The ice volume fraction is 0.7 . The effective particle size of externally mixed model and internally mixed model is $20 \mu \mathrm{m}$. In the co-exist model case, the volume ratios of the spherical water droplets, single column ice crystal, and coated sphere model are $15 \%, 35 \%$, and $50 \%$, respectively. $D_{e, i}=25.2 \mu \mathrm{m}$ and $D_{e, w}=13.4 \mu \mathrm{m}$.

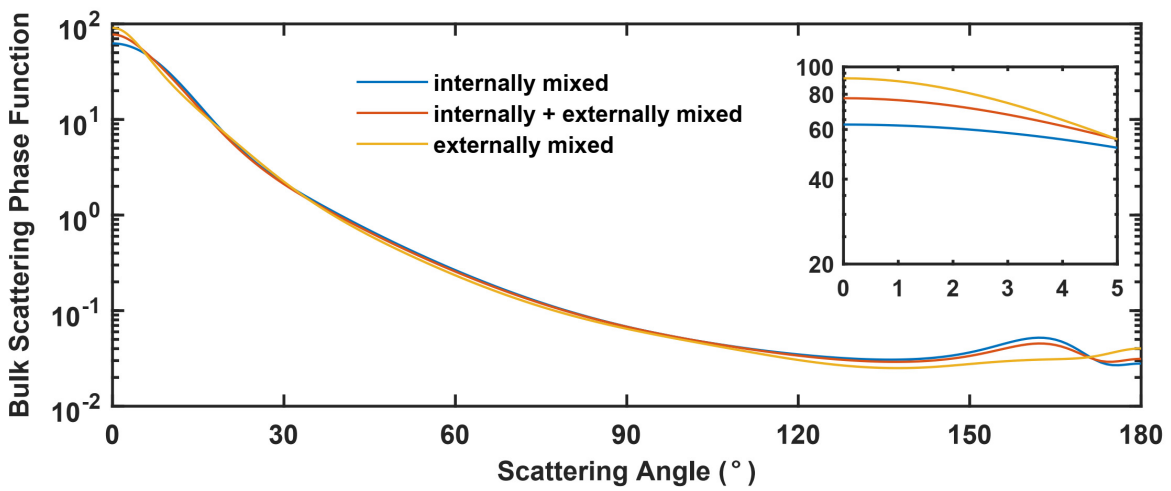

Figure 15. Bulk scattering phase function of three mixed models at the wavelength of $8 \mu \mathrm{m}$ where the ice volume fraction is 0.7 . The effective particle size of externally mixed model and internally mixed model is $20 \mu \mathrm{m}$. In the co-exist model case, the volume ratios of the spherical water droplets, single column ice crystal, and coated sphere model are $15 \%, 35 \%$, and $50 \%$, respectively. $D_{e, i}=25.2 \mu \mathrm{m}$ and $\mathrm{D}_{\mathrm{e}, \mathrm{w}}=13.4 \mu \mathrm{m}$. 


\section{Conclusions}

In this study, the optical properties of mixed-phase cloud were examined by assuming two cloud particle models, including the externally and internally mixed-phase cloud models. The computations are based on the latest advances in light scattering calculation technique (the invariant imbedding T-matrix method) and an available comprehensive ice scattering property database $[36,54]$. We follow the physical derivations conducted by Yang et al. [23] to calculate the optical properties of mixed-phase clouds. Analysis of the impacts of different ice particle morphologies and different cloud particle models over a broad wavelength range of 0.2 to $100 \mu \mathrm{m}$ is the main feature of this study.

With respect to the variations in mixed-phase cloud optical properties over the spectrum, similar patterns are found for the externally and internally mixed models when the same effective particle size is specified. However, the internally mixed model shows stronger variations in optical properties as the wavelength increases. Therefore, it is anticipated that the internally mixed cloud model could be potentially useful for radiative transfer modeling applications at certain wavelength ranges.

When the ice volume fraction is considered as the varying factor, it is shown that the ice volume fraction affects the internally and externally mixed cloud models differently, although similar variations in spectral optical properties can still be found. In particular, the spectral regions where ice volume fraction induces the largest perturbations are inconsistent in both models. This is especially true for variables such as asymmetry factor and extinction efficiency. Thus, the ice volume fraction is a key issue when the internally mixed model is used as a surrogate to calculate mixed-phase cloud properties.

Ice crystal habits are found to be a prominent factor that contribute to the differences among the optical properties of externally mixed-phase cloud particles where nine different ice habits are mixed with spherical liquid water droplets. Except for some strong absorbing bands, the extinction efficiency and asymmetry factor are sensitive to the ice habits. The largest differences in bulk asymmetry factors occurred in the mixture of spherical water droplet and 10-plate ice particles, as compared with the counterpart with spherical water droplet and 8-column ice aggregate mixture. In addition, the shape of ice crystal has a greater influence on the optical properties of the mixed-phase cloud when the effective diameter of ice crystals is smaller than $20 \mu \mathrm{m}$.

The ice volume fraction also affects the difference in the optical properties of the mixedphase cloud induced by the shape of ice crystal. With the increase of ice volume fraction, the shape of ice crystals has more obvious influence on the bulk extinction efficiency, scattering efficiency, and asymmetry factor of the mixed-phase cloud particles. It is interesting to confirm that a small fraction of inclusion of ice in the liquid water cloud (or vice versa) could induce significant changes in optical properties.

The internally mixed models (namely, the concentric spherical core-shell models) were also thoroughly examined in terms of the variations in their optical properties as compared to the externally mixed models. For the internally mixed model, the spectral region affected by the ice volume fraction mainly resides in the mid- to far-infrared spectral regions. It is also found that the calculated single scattering albedo of internally mixed-phase cloud show some agreements with the externally mixed counterpart in visible and near-infrared spectral band. However, the optical properties of the internally mixed model are much less sensitive to the changes in ice volume fraction than those in the externally mixed model. The results imply the necessity to examine the various factors before application is carried out. 
In terms of the bulk scattering phase function, the side and backscattering of the internally mixed model are also close to those of the externally mixed model at the longwave spectrum, although the phase function generally shows sphere-like features and weaker forward scattering peak. For the shortwave wavelengths, the difference in phase function becomes larger. The features found in phase functions correspond well with the variations in the asymmetry factors.

From the above discussions, it is evident that the optical properties of mixed-phase clouds depend on the relative amount of ice crystals and spherical water droplets, the effective diameter, the mixing mode, and the shape of ice crystals. The internally mixed model shows comparable optical properties with those of the conventional external model at some wavelengths. However, it is still important that detailed examination and testing are implemented before specific applications are carried out. Due to the limited observations of the mixed-phase cloud properties, it is hard to verify which of the mixed-phase cloud models is the optimal choice at this point. Advances in the observational techniques using active remote sensors could shed some light on this problem [61-63]. We only focus on analyzing the sensitivities of mixed-phase cloud properties to various microphysical factors in this study, and we only consider randomly oriented ice particles here, while prevalent oriented ice crystals in clouds are found and their optical properties are unique [38,64,65]. Further studies about the radiative effects caused by the different factors are under work and will be presented in the future.

Author Contributions: Conceptualization, Q.L. and B.Y.; Data curation, Q.L.; Methodology, Q.L. and B.Y.; Validation, Q.L., B.Y. and L.B. Visualization, Q.L.; Writing-original draft, Q.L., B.Y. and L.B.; Writing-review and editing, Q.L., B.Y. and L.B. All authors have read and agreed to the published version of the manuscript.

Funding: This study was supported by the National Natural Science Foundation of China (42075074 and 41775130), the Natural Science Foundation of Guangdong Province (2019A1515011230), and the funding to the Guangdong Province Key Laboratory for Climate Change and Natural Disaster Studies (2020B1212060025). Bingqi Yi acknowledged the support from Zhujiang Talent Program of Department of Science and Technology of Guangdong Province (2017GC010619).

Conflicts of Interest: The authors declare no conflict of interest.

\section{Appendix A}

Figure A1 shows the comparison result of the scattering phase function of the coated sphere model and the coated non-sphere model with various size parameters of shell and core at the wavelength of 0.65 and $8 \mu \mathrm{m}$. The results illustrate that the shape of the core has little effect on the scattering phase function of mixed-phase cloud. 

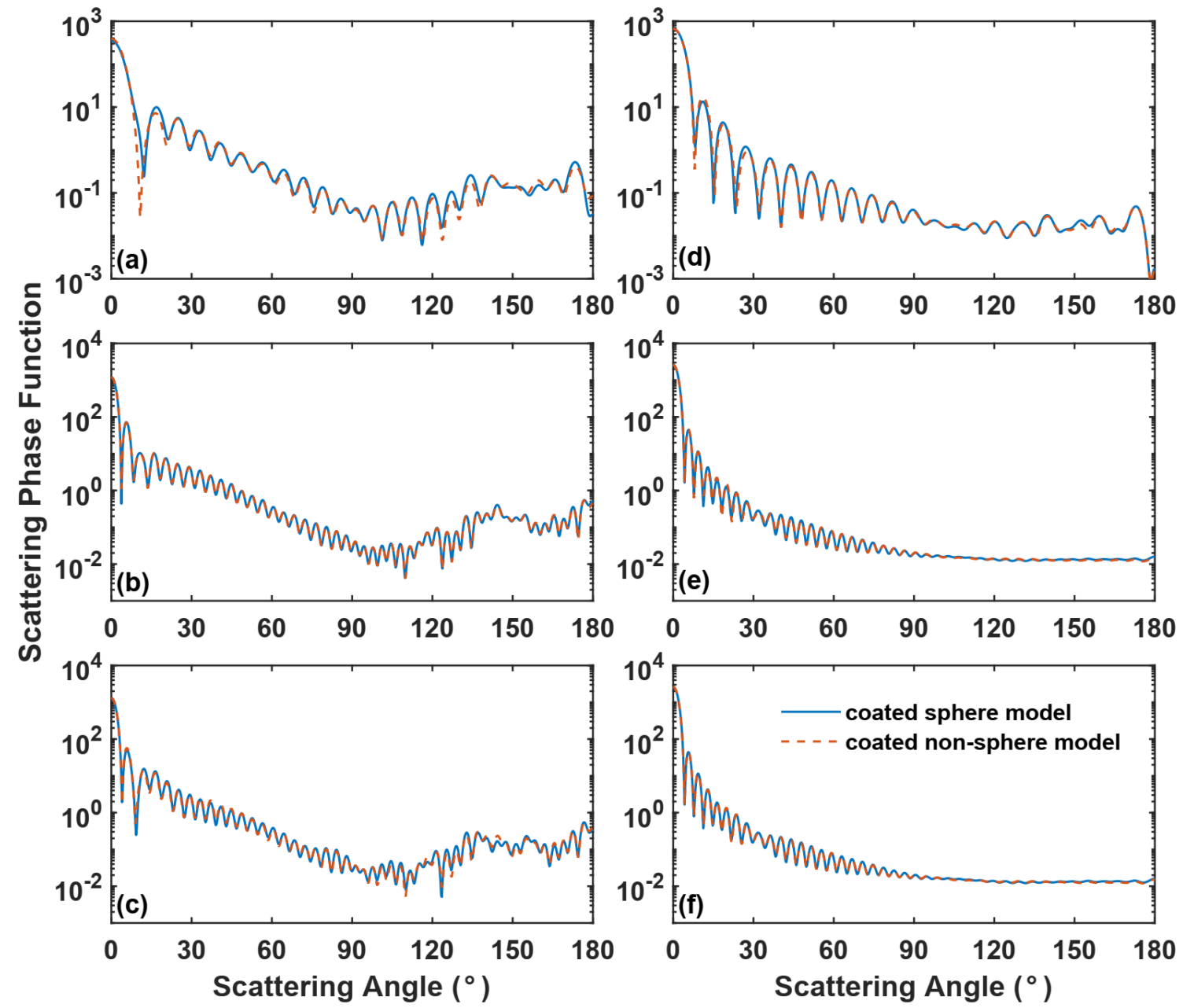

Figure A1. The scattering phase matrix of the coated sphere model and coated non-sphere model with various size parameters of shell and core at the wavelength of $0.65 \mu \mathrm{m}$ (left panels) and $8 \mu \mathrm{m}$ (right panels). (a,d) The size parameter of shell is 25. The size parameter of the core of the coated sphere model and coated non-sphere model is 15 and 17.7 , respectively; (b,e) The size parameter of shell is 50 . The size parameter of the core of the coated sphere model and coated non-sphere model is 15 and 17.7, respectively; $(\mathbf{c}, \mathbf{f})$ The size parameter of shell is 50 . The size parameter of the core of the coated sphere model and coated non-sphere model is 30 and 35.4, respectively.

\section{Appendix B}

When the liquid water droplet, ice crystal, and coated sphere model co-exists in the mixed-phase cloud, the following equation is used to calculate the bulk extinction efficiency of the mixed-phase cloud (the other variables follow similar equations):

$$
\begin{aligned}
& \overline{\mathrm{Q}}_{\mathrm{ext}}(\lambda)=\frac{f_{w} \int_{\mathrm{D}_{\min }}^{\mathrm{D}_{\max }} \mathrm{Q}_{\mathrm{ext}, w}(\mathrm{D}, \lambda) A_{w w}(\mathrm{D}) N_{w}(\mathrm{D}) \mathrm{dD}+f_{i} \int_{\mathrm{D}_{\min }}^{\mathrm{D} \max } \mathrm{Q}_{\mathrm{ext}, i}(\mathrm{D}, \lambda) A_{i}(\mathrm{D}) N_{i}(\mathrm{D}) \mathrm{dD}}{f_{w} \int_{\mathrm{D}_{\min }}^{\mathrm{D}_{\max }} A_{w}(\mathrm{D}) N_{w}(\mathrm{D}) \mathrm{dD}+f_{i} \int_{\mathrm{D}_{\min }}^{\mathrm{D}_{\max }} A_{i}(\mathrm{D}) N_{i}(\mathrm{D}) \mathrm{dD}+f_{c s} \int_{\mathrm{D}_{\min }}^{\mathrm{D}_{\max }} A_{c s}(\mathrm{D}) N_{c s}(\mathrm{D}) \mathrm{dD}}+ \\
& \frac{f_{c s} \int_{D_{\min }}^{\mathrm{D}_{\max }} Q_{\operatorname{ext}, c s}(\mathrm{D}, \lambda) A_{c s}(\mathrm{D}) N_{c s}(\mathrm{D}) \mathrm{dD}}{f_{w} \int_{\mathrm{D}_{\min }}^{\mathrm{D} \max } A_{w v}(\mathrm{D}) N_{w}(\mathrm{D}) \mathrm{d} \mathrm{D}+f_{i} \int_{\mathrm{D}_{\min }}^{\mathrm{D} \max } A_{i}(\mathrm{D}) N_{i}(\mathrm{D}) \mathrm{d} \mathrm{D}+f_{c s} \int_{\int_{\min }}^{\mathrm{D} \max } A_{c s}(\mathrm{D}) N_{c s}(\mathrm{D}) \mathrm{dD}},
\end{aligned}
$$

where $f_{i}, f_{w}$, and $f_{c s}$ are the volume ratio of ice crystal, spherical water droplet, and core-shell model, respectively.

$$
f_{w}=\frac{\int_{D_{\min }}^{D_{\max }} V_{w}(\mathrm{D}) N_{w}(\mathrm{D}) \mathrm{dD}}{\int_{\mathrm{D}_{\min }}^{\mathrm{D}_{\max }} V_{i}(\mathrm{D}) N_{i}(\mathrm{D}) \mathrm{dD}+\int_{\mathrm{D}_{\min }}^{D_{\max }} V_{w}(\mathrm{D}) N_{w}(\mathrm{D}) \mathrm{dD}+\int_{D_{\min }}^{D_{\max }} V_{c \mathcal{S}}(\mathrm{D}) N_{c \mathcal{S}}(\mathrm{D}) \mathrm{dD}},
$$




$$
\begin{aligned}
& f_{i}=\frac{\int_{D_{\min }}^{\mathrm{D}_{\max }} V_{i}(\mathrm{D}) N_{i}(\mathrm{D}) \mathrm{dD}}{\int_{\mathrm{D}_{\min }}^{\mathrm{D}_{\max }} V_{i}(\mathrm{D}) N_{i}(\mathrm{D}) \mathrm{dD}+\int_{\mathrm{D}_{\min }}^{\mathrm{D}_{\max }} V_{w}(\mathrm{D}) N_{w}(\mathrm{D}) \mathrm{dD}+\int_{\mathrm{D}_{\min }}^{\mathrm{D}_{\max }} V_{c s}(\mathrm{D}) N_{c s}(\mathrm{D}) \mathrm{dD}}, \\
& f_{c s}=\frac{\int_{D_{\min }}^{D_{\max }} V_{c s}(\mathrm{D}) N_{c s}(\mathrm{D}) \mathrm{dD}}{\int_{\mathrm{D}_{\min }}^{\mathrm{D}_{\max }} V_{i}(\mathrm{D}) N_{i}(\mathrm{D}) \mathrm{dD}+\int_{\mathrm{D}_{\min }}^{D_{\max }} V_{w}(\mathrm{D}) N_{w}(\mathrm{D}) \mathrm{dD}+\int_{\mathrm{D}_{\min }}^{\mathrm{D}_{\max }} V_{c S}(\mathrm{D}) N_{c s}(\mathrm{D}) \mathrm{dD}} .
\end{aligned}
$$

\section{References}

1. Ramanathan, V.; Cess, R.D.; Harrison, E.F.; Minnis, P.; Barkstrom, B.R.; Ahmad, E.; Hartmann, D. Cloud-Radiative Forcing and Climate: Results from the Earth Radiation Budget Experiment. Science 1989, 243, 57-63. [CrossRef] [PubMed]

2. Mitchell, J.F.B.; Senior, C.A.; Ingram, W.J. $\mathrm{CO}_{2}$ and Climate: A Missing Feedback? Nature 1989, 341, 132-134. [CrossRef]

3. Ebert, E.E.; Curry, J.A. A Parameterization of Ice Cloud Optical Properties for Climate Models. J. Geophys. Res. Atmos. 1992, 97, 3831-3836. [CrossRef]

4. McCoy, D.T.; Hartmann, D.L.; Grosvenor, D.P. Observed Southern Ocean Cloud Properties and Shortwave Reflection. Part I: Calculation of SW Flux from Observed Cloud Properties. J. Clim. 2014, 27, 8836-8857. [CrossRef]

5. Yan, Y.; Liu, X.; Liu, Y.; Lu, J. Comparison of Mixed-phase Clouds over the Arctic and the Tibetan Plateau: Seasonality and Vertical Structure of Cloud Radiative Effects. Clim. Dyn. 2020, 54, 4811-4822. [CrossRef]

6. Morrison, H.; Pinto, J. Intercomparison of Bulk Cloud Microphysics Schemes in Mesoscale Simulations of Springtime Arctic Mixed-Phase Stratiform Clouds. Mon. Wea. Rev. 2006, 134, 1880-1900. [CrossRef]

7. Barrett, A.I.; Hogan, R.J.; Forbes, R.M. Why are Mixed-phase Altocumulus Clouds Poorly Predicted by Large-scale Models? Part 1. Physical processes. J. Geophys. Res. Atmos. 2017, 122, 9903-9926. [CrossRef]

8. Korolev, A.; McFarquhar, G.; Field, P.R.; Franklin, C.; Lawson, P.; Wang, Z.; Borrmann, S. Mixed-phase Clouds: Progress and Challenges. Herpetol. Monographs 2017, 58, 5. [CrossRef]

9. Sun, Z.; Shine, K.P. Studies of the Radiative Properties of Ice and Mixed-Phase Clouds. Q. J. R. Meteorol. Soc. 1994, 120, 111-137. [CrossRef]

10. McFarquhar, G.M.; Cober, S.G. Single-Scattering Properties of Mixed-Phase Arctic Clouds at Solar Wavelengths: Impacts on Radiative Transfer. J. Clim. 2004, 17, 3799-3813. [CrossRef]

11. Korolev, A.V.; Isaac, G.A.; Cober, S.G.; Strapp, J.W.; Hallett, J. Microphysical Characterization of Mixed-phase Clouds. Q. J. R. Meteorol. Soc. 2003, 129, 39-65. [CrossRef]

12. Shupe, M.D.; Daniel, J.S.; De Boer, G.; Eloranta, E.W.; Kollias, P.; Long, C.N.; Luke, E.P.; Turner, D.D.; Verlinde, J. A Focus on Mixed-Phase Clouds: The Status of Ground-Based Observational Methods. Bull. Am. Meteorol. Soc. 2008, 89, 1549-1562. [CrossRef]

13. de Boer, G.; Eloranta, E.W.; Shupe, M.D. Arctic Mixed-Phase Stratiform Cloud Properties from Multiple Years of Surface-Based Measurements at Two High-Latitude Locations. J. Atmos. Sci. 2009, 66, 2874-2887. [CrossRef]

14. D'Alessandro, J.J.; Diao, M.; Wu, C.; Liu, X.; Jensen, J.B.; Stephens, B.B. Cloud Phase and Relative Humidity Distributions over the Southern Ocean in Austral Summer Based on In Situ Observations and CAM5 Simulations. J. Clim. 2019, 32, 2781-2805. [CrossRef]

15. Sassen, K. Evidence for Liquid-Phase Cirrus Cloud Formation from Volcanic Aerosols: Climatic Implications. Science 1992, 257, 516-519. [CrossRef] [PubMed]

16. Sun, Z; Shine, K.P. Parameterization of Ice Cloud Radiative Properties and Its Application to the Potential Climatic Importance of Mixed-Phase Clouds. J. Clim. 1995, 8, 1874-1888. [CrossRef]

17. Cober, S.G.; Isaac, G.A.; Korolev, A.V.; Strapp, J.W. Assessing Cloud-Phase Conditions. J. Appl. Meteorol. Climatol. 2001, 40, 1967-1983. [CrossRef]

18. Vidaurre, G.; Hallett, J. Ice and Water Content of Stratiform Mixed-phase Cloud. Q. J. R. Meteorol. Soc. 2010, 135, 1292-1306. [CrossRef]

19. Shupe, M.D.; Uttal, T.; Matrosov, S.Y.; Frisch, A.S. Cloud water contents and hydrometeor sizes during the FIRE Arctic Clouds Experiment. J. Geophys. Res. Atmos. 2001, 106, 15015-15028. [CrossRef]

20. Lee, J.; Yang, P.; Dessler, A.E.; Baum, B.A.; Platnick, S. The Influence of Thermodynamic Phase on the Retrieval of Mixed-Phase Cloud Microphysical and Optical Properties in the Visible and near-Infrared Region. IEEE Geosci. Remote. Sens. Lett. 2006, 3, 287-291. [CrossRef]

21. Sassen, K.; Khvorostyanov, V.I. Microphysical and Radiative Properties of Mixed-Phase Altocumulus: A Model Evaluation of Glaciation Effects. Atmos. Res. 2007, 84, 390-398. [CrossRef]

22. Tan, I.; Storelvmo, T.; Zelinka, M.D. Observational Constraints on Mixed-Phase Clouds Imply Higher Climate Sensitivity. Science 2016, 352, 224-227. [CrossRef]

23. Yang, P.; Wei, H.L.; Baum, B.A.; Huang, H.L.; Heymsfield, A.J.; Hu, Y.X.; Turner, D.D. The Spectral Signature of Mixed-Phase Clouds Composed of Non-Spherical Ice Crystals and Spherical Liquid Droplets in the Terrestrial Window Region. J. Quant. Spectrosc. Radiat. Transf. 2003, 79, 1171-1188. [CrossRef] 
24. Sikand, M.; Koskulics, J.; Stamnes, K.; Hamre, B.; Stamnes, J.J.; Lawson, R.P. Estimation of Mixed-Phase Cloud Optical Depth and Position Using In Situ Radiation and Cloud Microphysical Measurements Obtained from a Tethered-Balloon Platform. J. Atmos. Sci. 2013, 70, 317-329. [CrossRef]

25. Ehrlich, A.; Wendisch, M.; Bierwirth, E.; Herber, A.; Schwarzenböck, A. Ice crystal shape effects on solar radiative properties of Arctic mixed-phase clouds-Dependence on microphysical properties. Atmos. Res. 2008, 88, 266-276. [CrossRef]

26. Harrington, J.Y.; Olsson, P.Q. A Method for the Parameterization of Cloud Optical Properties in Bulk and Bin Microphysical Models. Implications for Arctic Cloudy Boundary Layers. Atmos. Res. 2001, 57, 51-80. [CrossRef]

27. Ramaswamy, V.; Detwiler, A. Interdependence of Radiation and Microphysics in Cirrus Clouds. J. Atmos. Sci. 1986, 43, $2289-2301$. [CrossRef]

28. Liou, K.-N. Electromagnetic Scattering by Arbitrarily Oriented Ice Cylinders. Appl. Opt. 1972, 11, 667-674. [CrossRef] [PubMed]

29. Fu, Q.; Liou, K.N. Parameterization of the Radiative Properties of Cirrus Clouds. J. Atmos. Sci. 1993, 50, 2008-2025. [CrossRef]

30. Lawson, R.P.; Baker, B.A.; Schmitt, C.G.; Jensen, T.L. An Overview of Microphysical Properties of Arctic Clouds Observed in May and July 1998 during FIRE ACE. J. Geophys. Res. 2001, 106, 14989-15014. [CrossRef]

31. Fleishauer, R.P.; Larson, V.E.; Haar, T.H.V. Observed Microphysical Structure of Midlevel, Mixed-Phase Clouds. J. Atmos. Sci. 2002, 59, 1779-1804. [CrossRef]

32. Baker, B.A.; Lawson, R.P. In Situ Observations of the Microphysical Properties of Wave, Cirrus, and Anvil Clouds. Part II: Cirrus Clouds. J. Atmos. Sci. 2006, 63, 3160-3185. [CrossRef]

33. Bailey, M.P.; Hallett, J. A Comprehensive Habit Diagram for Atmospheric Ice Crystals: Confirmation from the Laboratory, AIRS II, and Other Field Studies. J. Atmos. Sci. 2009, 66, 2888-2899. [CrossRef]

34. Key, J.R.; Yang, P.; Baum, B.A.; Nasiri, S.L. Parameterization of Shortwave Ice Cloud Optical Properties for Various Particle Habits. J. Geophys. Res. 2002, 107, 4181. [CrossRef]

35. Yang, P.; Wei, H.; Huang, H.-L.; Baum, B.A.; Hu, Y.X.; Kattawar, G.W.; Fu, Q. Scattering and Absorption Property Database for Nonspherical Ice Particles in the near- through Far-Infrared Spectral Region. Appl. Opt. 2005, 44, 5512-5523. [CrossRef] [PubMed]

36. Yang, P.; Bi, L.; Baum, B.A.; Liou, K.-N.; Kattawar, G.W.; Mishchenko, M.I.; Cole, B. Spectrally Consistent Scattering, Absorption, and Polarization Properties of Atmospheric Ice Crystals at Wavelengths from 0.2 to $100 \mu \mathrm{m}$. J. Atmos. Sci. 2013, 70, 330-347. [CrossRef]

37. Letu, H.; Ishimoto, H.; Riedi, J.; Nakajima, T.Y.; Sekiguchi, M. Investigation of Ice Particle Habits to Be Used for Ice Cloud Remote Sensing for the GCOM-C Satellite Mission. Atmos. Chem. Phys. 2015, 15, 31665-31703. [CrossRef]

38. Saito, M.; Yang, P. Oriented Ice Crystals: A Single-Scattering Property Database for Applications to Lidar and Optical Phenomenon Simulations. J. Atmos. Sci. 2019, 76, 2635-2652. [CrossRef]

39. Chen, Q.; Zhang, H. Effects of ice crystal habit weight on ice cloud optical properties and radiation. Acta Meteorol. Sin. 2018, 76, 279-288. [CrossRef]

40. Miles, N.L.; Verlinde, J.; Clothiaux, E.E. Cloud Droplet Size Distributions in Low-Level Stratiform Clouds. J. Atmos. Sci. 2000, 57, 295-311. [CrossRef]

41. Hansen, J.E. Multiple Scattering of Polarized Light in Planetary Atmospheres Part II. Sunlight Reflected by Terrestrial Water Clouds. J. Atmos. Sci. 1971, 28, 1400-1426. [CrossRef]

42. Ulbrich, C.W. Natural Variations in the Analytical Form of the Raindrop Size Distribution. J. Appl. Meteorol. 1983, 22, 1764-1775. [CrossRef]

43. Morrison, H.; Curry, J.A.; Khvorostyanov, V.I. A New Double-Moment Microphysics Parameterization for Application in Cloud and Climate Models. Part I: Description. J. Atmos. Sci. 2005, 62, 1665-1677. [CrossRef]

44. Sekhon, R.S.; Srivastava, R.C. Snow Size Spectra and Radar Reflectivity. J. Atmos. Sci. 1970, 27, 299-307. [CrossRef]

45. Jacobson, M.Z. Strong Radiative Heating Due to the Mixing State of Black Carbon in Atmospheric Aerosols. Nature 2001, 409, 695-697. [CrossRef] [PubMed]

46. Liu, D.; Whitehead, J.; Alfarra, M.R.; Reyes-Villegas, E.; Spracklen, D.V.; Reddington, C.L.; Haslett, S. Black-Carbon Absorption Enhancement in the Atmosphere Determined by Particle Mixing State. Nat. Geosci. 2017, 10, 184-188. [CrossRef]

47. Zhou, C.; Zhang, H.; Zhao, S.; Li, J. On Effective Radiative Forcing of Partial Internally and Externally Mixed Aerosols and Their Effects on Global Climate. J. Geophys. Res. 2018, 123, 401-423. [CrossRef]

48. Wang, Z.; Bi, L.; Yi, B.; Zhang, X. How the Inhomogeneity of Wet Sea Salt Aerosols Affects Direct Radiative Forcing. Geophys. Res. Lett. 2019, 46, 1805-1813. [CrossRef]

49. Bi, L.; Yang, P.; Kattawar, G.W.; Mishchenko, M.I. Efficient Implementation of the Invariant Imbedding T-Matrix Method and the Separation of Variables Method Applied to Large Nonspherical Inhomogeneous Particles. J. Quant. Spectrosc. Radiat. Transf. 2013, 116, 169-183. [CrossRef]

50. Bi, L.; Yang, P.; Kattawar, G.W.; Mishchenko, M.I. A Numerical Combination of Extended Boundary Condition Method and Invariant Imbedding Method Applied to Light Scattering by Large Spheroids and Cylinders. J. Quant. Spectrosc. Radiat. Transf. 2013, 123, 17-22. [CrossRef]

51. Bi, L.; Yang, P. Accurate Simulation of the Optical Properties of Atmospheric Ice Crystals with the Invariant Imbedding T-Matrix Method. J. Quant. Spectrosc. Radiat. Transf. 2014, 138, 17-35. [CrossRef]

52. Bi, L.; Lin, W.; Wang, Z.; Tang, X.; Zhang, X.; Yi, B. Optical Modeling of Sea Salt Aerosols: The Effects of Nonsphericity and Inhomogeneity. J. Geophys. Res. 2018, 123, 543-558. [CrossRef] 
53. Bohren, C.F.; Huffman, D.R. Absorption and Scattering of Light by Small Particles; Wiley-VCH Verlag GmbH \& Co. KgaA: Weinheim, Germany, 1998. Available online: https:/ / onlinelibrary.wiley.com/doi/book/10.1002/9783527618156 (accessed on 11 June 2021).

54. Bi, L.; Yang, P. Improved Ice Particle Optical Property Simulations in the Ultraviolet to Far-Infrared Regime. J. Quant. Spectrosc. Radiat. Transf. 2017, 189, 228-237. [CrossRef]

55. Warren, S.G.; Brandt, R.E. Optical Constants of Ice from the Ultraviolet to the Microwave: A Revised Compilation. J. Geophys. Res. Atmos. 2008, 113. [CrossRef]

56. Hale, G.M.; Querry, M.R. Optical Constants of Water in the 200-nm to 200- $\mathrm{mm}$ Wavelength Region. Appl. Opt. 1973, 12, 555-563. [CrossRef] [PubMed]

57. Palmer, K.F.; Williams, D. Optical Properties of Water in the near Infrared. J. Opt. Soc. Amer. 1974, 64, 1107-1110. [CrossRef]

58. Downing, H.D.; Williams, D. Optical Constants of Water in the Infrared. J. Geophys. Res. 1975, 80, 1656-1661. [CrossRef]

59. Baum, B.A.; Yang, P.; Heymsfield, A.J.; Schmitt, C.G.; Xie, Y.; Bansemer, A.; Zhang, Z. Improvements in Shortwave Bulk Scattering and Absorption Models for the Remote Sensing of Ice Clouds. J. Appl. Meteorol. Climatol. 2011, 50, 1037-1056. [CrossRef]

60. Arnott, W.P.; Dong, Y.Y.; Hallett, J. Extinction Efficiency in the Infrared $(2-18 \mu \mathrm{m})$ of Laboratory Ice Clouds: Observations of Scattering Minima in the Christiansen Bands of Ice. Appl. Opt. 1995, 34, 541-551. [CrossRef] [PubMed]

61. Avery, M.A.; Ryan, R.A.; Getzewich, B.J.; Vaughan, M.A.; Winker, D.M.; Hu, Y.; Garnier, A.; Pelon, J.; Verhappen, C.A. CALIOP V4 cloud thermodynamic phase assignment and the impact of near-nadir viewing angles. Atmos. Meas. Tech. 2020, 13, 4539-4563. [CrossRef]

62. Liu, D.; Liu, Q.; Qi, L.; Fu, Y. Oceanic single-layer warm clouds missed by the Cloud Profiling Radar as inferred from MODIS and CALIOP measurements. J. Geophys. Res. Atmos. 2016, 121, 12947-12965. [CrossRef]

63. Luo, T.; Wang, Z.; Li, X.; Deng, S.; Huang, Y.; Wang, Y. Retrieving the polar mixed-phase cloud liquid water path by combining CALIOP and IIR measurements. J. Geophys. Res. Atmos. 2018, 123, 1755-1770. [CrossRef]

64. Bréon, F.-M.; Dubrulle, B. Horizontally oriented plates in clouds. J. Atmos. Sci. 2004, 61, 2888-2898. [CrossRef]

65. Zhou, C.; Yang, P.; Dessler, A.E.; Hu, Y.; Baum, B.A. Study of horizontally oriented ice crystals with CALIPSO observations and comparison with Monte Carlo radiative transfer simulations. J. Appl. Meteor. Climatol. 2012, 51, 1426-1439. [CrossRef] 